\title{
Numerical Study of the Effects of Topography and Urbanization on the Local Atmospheric Circulations over the Beijing-Tianjin-Hebei, China
}

\author{
Yucong Miao, ${ }^{1}$ Shuhua Liu,, ${ }^{1}$ Yijia Zheng, ${ }^{1}$ Shu Wang, ${ }^{1}$ and Bicheng Chen ${ }^{2}$ \\ ${ }^{1}$ Department of Atmospheric and Oceanic Sciences, School of Physics, Peking University, Beijing 100871, China \\ ${ }^{2}$ Department of Meteorology, The Pennsylvania State University, University Park, PA 16802, USA \\ Correspondence should be addressed to Shuhua Liu; lshuhua@pku.edu.cn
}

Received 16 June 2014; Accepted 13 August 2014

Academic Editor: Sultan Al-Yahyai

Copyright (C) 2015 Yucong Miao et al. This is an open access article distributed under the Creative Commons Attribution License, which permits unrestricted use, distribution, and reproduction in any medium, provided the original work is properly cited.

\begin{abstract}
The effects of the topography and urbanization on the local atmospheric circulations over the Beijing-Tianjin-Hebei (BTH) region were studied by the weather research and forecasting (WRF) model, as well as the interactions among these local atmospheric circulations. It was found that, in the summer day time, the multiscale thermally induced local atmospheric circulations may exist and interact in the same time over the BTH region; the topography played a role in the strengthening of the sea breeze circulations; after sunset, the inland progress of sea breeze was slowed down by the opposite mountain breeze; when the land breeze circulation dominated the Bohai bay, the mountain breeze circulation can couple with the land breeze circulation to form a large circulation ranging from the coastline to the mountains. And the presence of cities cannot change the general state of the sea-land breeze (SLB) circulation and mountain-valley breeze (MVB) circulation but acted to modify these local circulations slightly. Meanwhile, the development of the urban heat island (UHI) circulation was also strongly influenced by the nearby SLB circulation and MVB circulation.
\end{abstract}

\section{Introduction}

The Beijing-Tianjin-Hebei region (BTH), located in North China Plain, is one of China's most economically developed regions, with a region of 216,000 square $\mathrm{km}$ in size and over 100 million in population. Facing the Bohai Sea, the $\mathrm{BTH}$ region is frequently under the influence of sea-land breeze (SLB) circulations during summertime; besides, the $\mathrm{BTH}$ region is located in a mountainous area, which is also affected by the mountain-valley breeze (MVB) circulation. In addition, the rapid urbanization process $[1,2]$ of BTH has resulted in significant urban heat island (UHI) phenomenon there [3], characterized by the temperature variation between a city and its suburb rural areas and the thermally induced UHI circulation.

The local atmospheric circulations play an important role in the local air quality and the boundary-layer structure [4-8]. Chen et al. reported the mountain-chimney effect on the distribution of air pollutants of Beijing by using aircraft measurements [9]. Wang et al. suggested that the
MVB circulation can transport the urban pollutants to the mountain areas [10]. The study of Lo et al. showed that urbanization enhanced the pollutant trapping and therefore contributes to the overall poor air quality in the Pearl River Delta [11]. And these local atmospheric circulations can couple and interact [12]. Lo et al. set up a number of numerical experiments by numerical model to investigate the impacts of urbanization and its associated UHI on the local- and regional-scale atmospheric circulations over the Pearl River Delta, and it was found that stronger UHI in the Pearl River Delta enhances the mesoscale sea-breeze circulation [13]. The study of Freitas et al. found that the presence of the urban region increased the sea-breeze front propagation mean speed by about $0.32 \mathrm{~m} \mathrm{~s}^{-1}$ when compared with the situation of no city [14]. The work of Miao et al. [15] and Nitis et al. [16] demonstrated that topography played an important role in the sea-breeze circulation.

Recently, the Chinese central government is considering plans to upgrade regional cooperation between Beijing, 
Tianjin, and Hebei province to build a trilateral economic sphere in the Bohai Bay area to become China's third economic engine, alongside the Pearl and Yangtze River Deltas. However, the rapid urbanization has been causing several environmental impacts in the BTH region, such as the heavy haze pollution [17-19]. To better manage the rapidly deteriorating air quality in the $\mathrm{BTH}$ region and achieve sustainable development, a better understanding of the local atmospheric circulations of the $\mathrm{BTH}$ region is necessary, including the complex interactions among the SLB circulation, MVB circulation, and the UHI circulation, which is rarely investigated.

In this study, the interactions among these local atmospheric circulations over the BHT region were investigated by using the weather research and forecasting (WRF) model. First, the effects of the topography and urbanization on the local atmospheric circulations over the BTH region were investigated by using the idealized initial and boundary conditions. And then the idealized schematic local atmospheric circulations were summed up and compared with the realistic simulated circulations.

The remainder of the paper is organized as follows. In Section 2, the mesoscale model and numerical experiments setup are described. In Section 3, the numerical results are presented, and the effects of topography and urbanization are discussed. Finally, the conclusions are given in Section 4.

\section{Models Description and Numerical Setup}

The mesoscale meteorological model used is the WRF model version 3.5. In order to properly treat the complex topography and land use of North China Plain, 2 two-way nested domains are used in this study (Figure 1(a)). The inner domain is a $2 \mathrm{~km}$ fine-resolution domain, covering Beijing, Tianjin, and four big cities (Baoding, Langfang, Cangzhou, and Tangshan) of Hebei province around the Bohai Bay (Figure 1(b)). Table 1 lists the details of domain configurations and physics parameterization schemes used. There are 55 vertical layers from the surface to the $50 \mathrm{hPa}$ level used to resolve the local atmospheric circulation features. The WRF single-moment 5class scheme (WSM5) [20] used for cloud physical process has been employed. The radiation processes are handled using the updated rapid radiative transfer model (RRTMG) [21]. The Yonsei University (YSU) planet boundary layer (PBL) scheme [22] is used. The Noah land surface model (LSM) [23] with a single-layer urban canopy model (UCM) $[24,25]$ is used for the land surface process. The single-layer model is used to parameterize the effects of urban canopy geometry on the surface energy and low level wind shear, and the urban canopy parameters are set by referring to the study of Wang et al. [26].

Since the land surface has been changed a lot in the North China Plain caused by the urbanization process in the past two decades, the latest global land use dataset called GlobCover 2009 [27] is applied in this research. The GlobCover 2009 is $300 \mathrm{~m}$ spatial resolution land cover dataset obtained by the MERIS (the medium resolution imaging spectrometer)
TABLE 1: Domain configurations and physics options of the WRF simulation.

\begin{tabular}{lc}
\hline & $\begin{array}{c}\text { Domain configurations and } \\
\text { physics options }\end{array}$ \\
\hline Domain dimensions & $145 \times 211,120 \times 175$ \\
Grid size & $6 \mathrm{~km}, 2 \mathrm{~km}$ \\
Vertical layers & 55 \\
Vertical layers below $1500 \mathrm{~m}$ & 35 \\
Microphysics scheme & WSM 5-class scheme \\
Cumulus scheme & None \\
Radiation scheme & RRTMG \\
Land surface scheme & Noah LSM with UCM \\
PBL scheme & YSU \\
\hline
\end{tabular}

sensor on board the ENVISAT satellite mission during 1 January, 2009, and 31 December, 2009.

To investigate the typical features of the local- and regional-scale atmospheric circulations and to separate them from other complexities of the real atmosphere, idealized meteorological initial and boundary conditions are firstly ingested into the WRF simulations. Since the SLB circulation and MVB circulation are common phenomena during the summer months, a period of summer months (i.e., June, July, and August) is selected in this study. For the idealized numerical simulation, the initial and boundary conditions are built with the 6-hourly $1^{\circ} \times 1^{\circ}$ NCEP final analysis (FNL) data from 0600 UTC 24 August, 2013, to 0000 UTC 25 August, 2013. The idealized initial and boundary conditions are created by averaging the domain sea-level pressure and geopotential height at each upper level, to provide a stationary synoptic condition. The wind components below and above the $750 \mathrm{hPa}$ level are specified by $0 \mathrm{~m} \mathrm{~s}^{-1}$ and the average values of each level, respectively. The relative humidity (RH) is multiplied by a factor of 0.25 to avoid the influences of cloud, and the value of 0.25 is given by several sensitivity experiments. The 42 -hourly idealized simulation is consisted of two phases $(18+24 \mathrm{hr})$. The first 18 hours from 0600 UTC 24 August to 0000 UTC 25 August is run as the spin-up, which is the first phase of the simulation. And then the simulation at 0000 UTC 25 August from the first phase is used as the initial condition for the second phase $24 \mathrm{~h}$ simulation, recalculated from 0000 UTC (0800 LST) 24 August to 0000 UTC (0800 LST) 25 August by using the same idealized boundary conditions. The interval of the model output is one hour.

The numerical experiment run by using the GlobCover 2009, the idealized initial and boundary conditions, is regard as the control run (hereafter referred as CNTL). The other two idealized experiments carried out to determine the effects of the topography and urbanization are identical to the control run, except for the changes of the topography (FLAT experiment) and urban land use (RURAL experiment) (Table 2).

To investigate of the effect of the synoptic forcing on the local atmospheric circulations, another numerical experiment (REAL) using the same numerical configurations is 


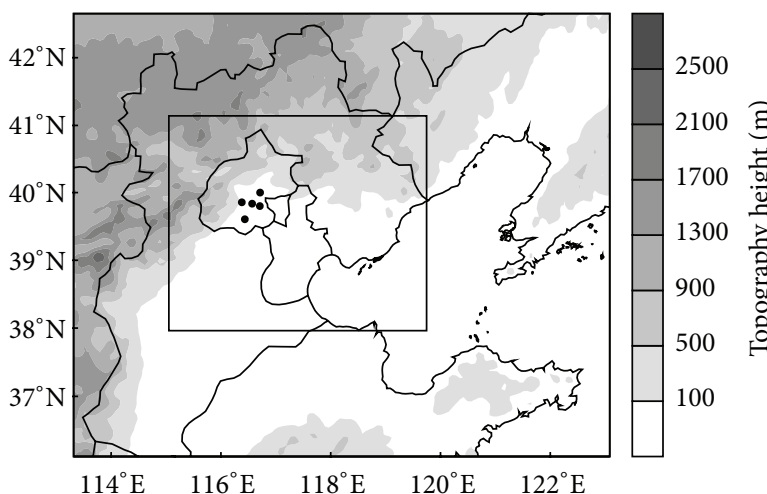

(a)

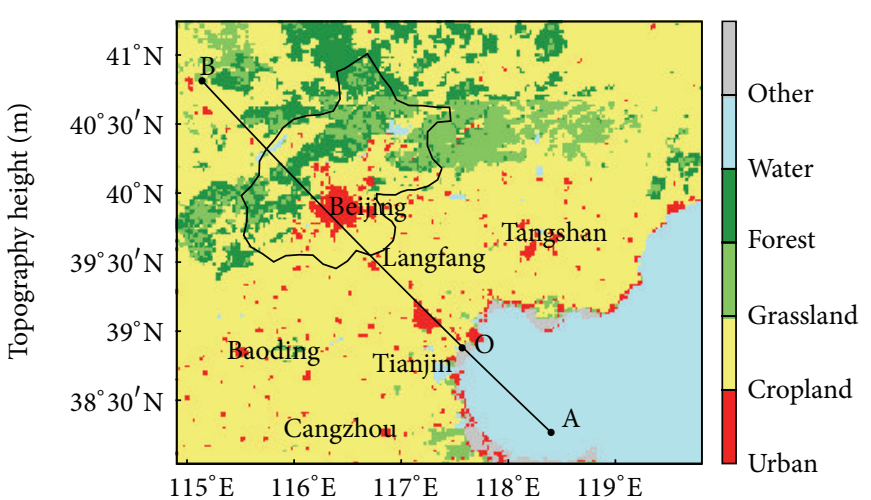

(b)

FIGURE 1: (a) The topography height of the nested domains and (b) the land use category of the inner domain. The rectangle in (a) indicates the location of inner domain. The solid line in (b) indicates the route of the vertical cross section made from point $A$ to point $B$ given in Figures 6-8 and Figures 11-15, and the point O located at the border of land and sea is used as the reference point $(0,0)$ in the vertical cross section. The black dots in Figure 1(a) indicate the location of the five meteorological stations used to validate the WRF simulation.

TABLE 2: Summary of the numerical experiments.

\begin{tabular}{lccc}
\hline Experiment & Land use & Topography & Initial and boundary conditions \\
\hline CNTL & GlobCover 2009 & Realistic terrain & Idealized conditions \\
FLAT & GlobCover 2009 & Flat terrain & Idealized conditions \\
RURAL & Change urban grids to cropland grids & Realistic terrain & Idealized conditions \\
REAL & GlobCover 2009 & Realistic terrain & Realistic conditions \\
\hline
\end{tabular}

carried out, except for the use of the realistic NCEP FNL initial and boundary conditions. The REAL experiment is integrated from 1200 UTC 23 August, 2013, to 0000 UTC 25 August, 2013, and the first 12 hours simulation is run as the spin-up (Table 2). During the simulation period, the BTH region was dominated by a high pressure synoptic system; under this weak synoptic condition, the local atmospheric circulations were well established.

\section{Results and Discussions}

In this part, the WRF simulated results (REAL experiment) are firstly evaluated by using the measurements from the ground-based stations (Figure 1(a) and Table 3). And then the effects of the topography and the urbanization process are presented and discussed.

3.1. The Evaluation of WRF Simulation. The $2 \mathrm{~km}$ resolution WRF simulation of the REAL experiment is evaluated by comparing with the measurements $(2 \mathrm{~m}$ temperature, $10 \mathrm{~m}$ wind speed, and wind direction) of five ground-based stations around Beijing (Figure 1(a) and Table 3). It is found that, at night, the simulated temperatures at Haidian, Chaoyang, and Fengtai stations are slightly higher than the measurements at night (Figures 2(b), 2(d), and 2(e)). Despite this discrepancy, the diurnal cycle of surface temperature is well simulated.

As depicted in Figure 3, during the simulation period, the surface wind speed is relatively low during the simulated period, with a value lower than $4 \mathrm{~m} \mathrm{~s}^{-1}$ at most times of the simulation period. Comparing with the measurements, it is noted that the $10 \mathrm{~m}$ wind speeds at Haidian and Fengtai stations (Figures 3(b) and 3(e)) are slightly overestimated by the WRF model. Despite this discrepancy of wind speed simulation, most of the fluctuation characteristics and variation trend of wind speed at the five sites during the simulation period can be well replicated by the WRF model.

A typical MVB pattern over the Beijing region can be observed from the time series of wind direction (Figure 4). In the early morning, the Beijing area is dominated by the cold northern mountain-breeze. By noon, as the mountain areas are warmed by the sun, the dominant wind over the Beijing area turns into the warmed southern valley-breeze. At night, as the mountain areas are cooled by nocturnal radiation, the southern valley-breeze disappears gradually and replaces by the northern down-slope mountain-breeze. The evolution of the diurnal MVB circulation is well simulated by the WRF model during the simulated period.

From this preliminary validation, it is found that the WRF model used in this study is capable of replicating the atmospheric conditions over the BTH region.

3.2. Effects of Topography on the Sea Breeze Circulation. To investigate the difference of the topography in producing and modifying the SLB circulation, the evolution of the $10 \mathrm{~m}$ horizontal wind field is given in Figure 5. And the vertical cross sections of the wind field along the solid line in Figure 1(b) are shown in Figures 6 and 7. 

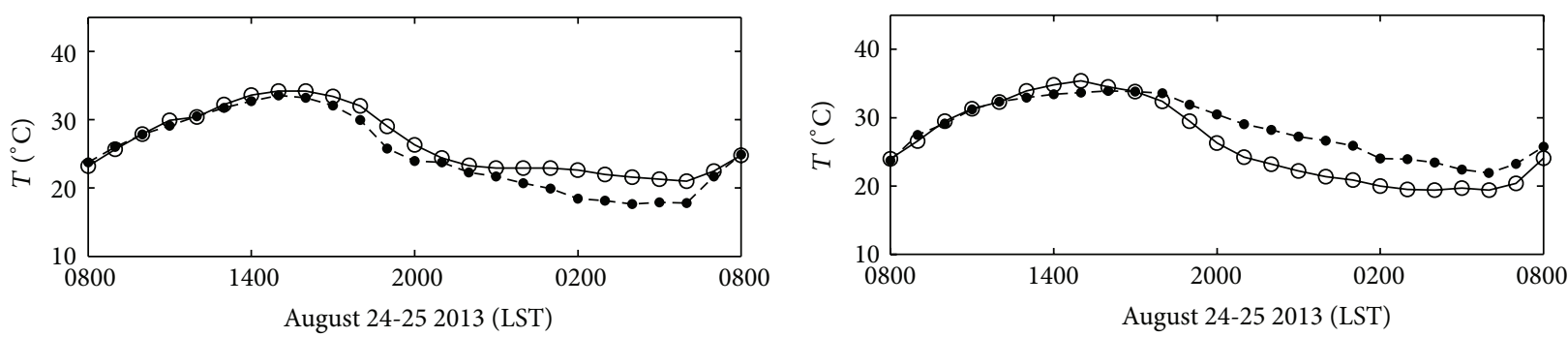

- Obs

- - Sim

(a)

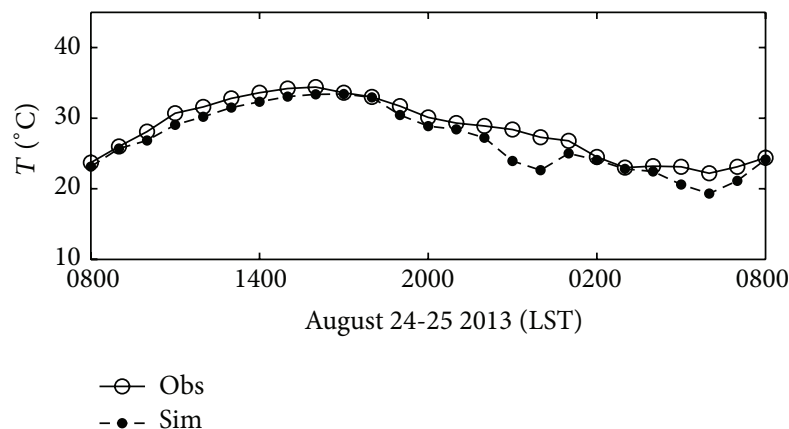

(b)

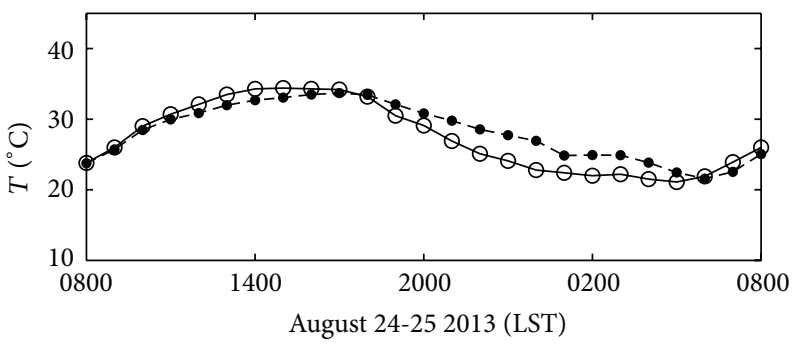

-O Obs

-•- Sim

(c)

(d)

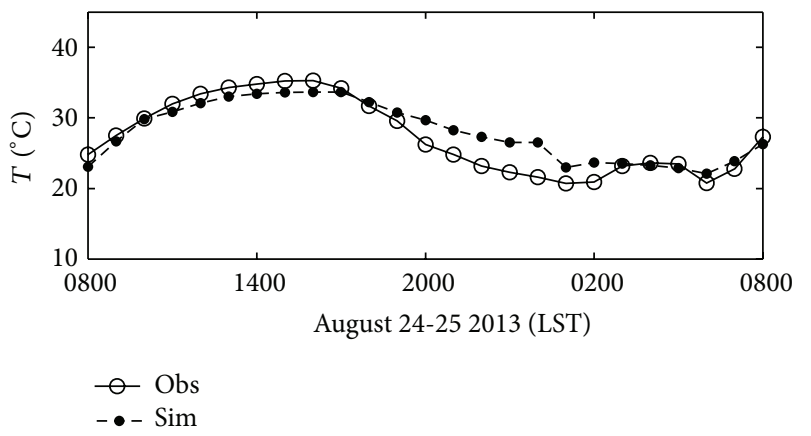

(e)

Figure 2: Time series of observed and simulated $2 \mathrm{~m}$ temperature $\left({ }^{\circ} \mathrm{C}\right)$. (a) Shunyi, (b) Haidian, (c) Tongzhou, (d) Chaoyang, and (e) Fengtai. The simulations are obtained from the grids nearest to the stations.

TABLE 3: The locations and altitudes of the meteorological stations given in Figure 1(a).

\begin{tabular}{lcccc}
\hline ID & Station & Longitude $\left(^{\circ}\right)$ & Latitude $\left({ }^{\circ}\right)$ & Altitude $(\mathrm{m})$ \\
\hline 54398 & Shunyi & 116.617 & 40.117 & 29.6 \\
54399 & Haidian & 116.267 & 39.967 & 46.9 \\
54431 & Tongzhou & 116.617 & 39.917 & 40.6 \\
54433 & Chaoyang & 116.467 & 39.95 & 36.5 \\
54514 & Fengtai & 116.25 & 39.867 & 57 \\
\hline
\end{tabular}

In the CNTL experiment, the wind begins to blow onshore at around 0900 LST (Figure 5(a)), indicating the onset of the sea breeze, while the land breeze is still dominant over the coastal regions of FLAT experiment (Figure 5(b)). Meanwhile, the mountains located on the north and west of Hebei province are warmed by the sunlight, and they warm the adjacent air to become the thermally induced upward valley breezes. However, at the early moment (before 1100 LST) the valley breeze circulation is not strong enough to affect the distant sea breeze circulation.

As depicted in Figure 6(a), by noon (1200 LST), as the mountain continues to be warmed by the sun, the valley breeze circulation becomes stronger and starts to play a role in the development of the sea breeze circulation. At 1200 LST, the warm upward valley wind can reach the altitude of 3$4 \mathrm{~km}$ over the mountain areas and then turns into the aloft antivalley wind, blowing from the mountain areas to the sea. At the upper level, as the air parcels flow toward the sea, the air parcels become cooled and denser; therefore, when the air parcels reach the coastline, some of them would descend to the surface level and participate in the sea breeze circulation 


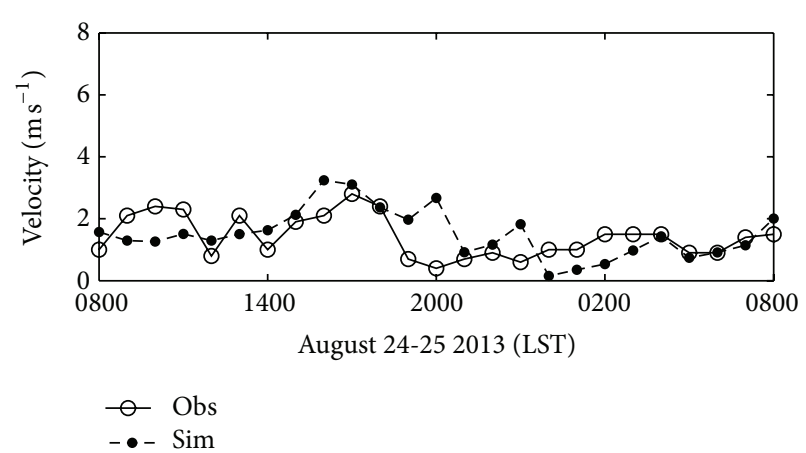

(a)

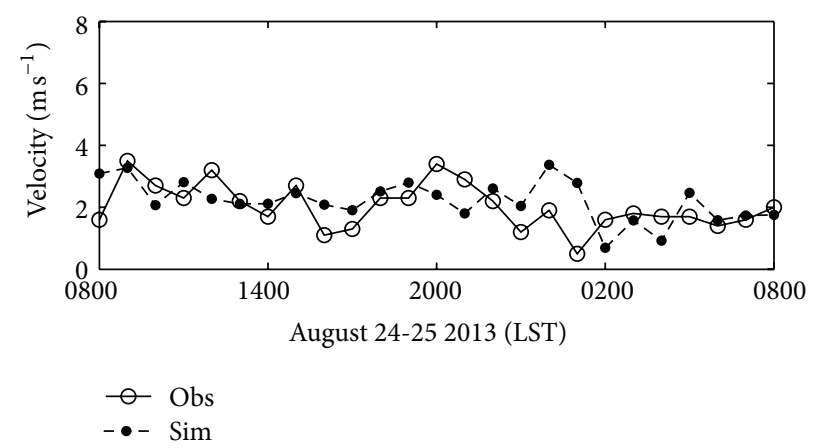

(c)

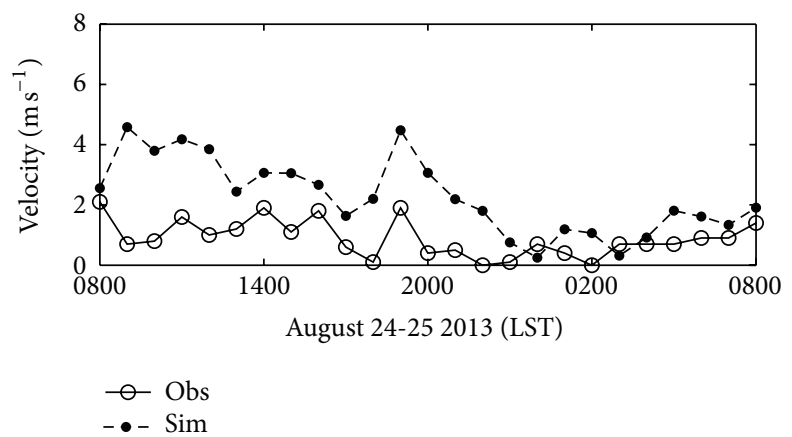

(b)

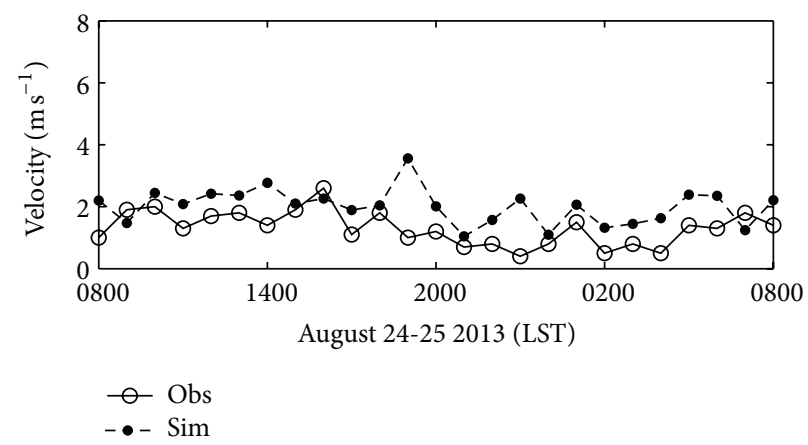

(d)

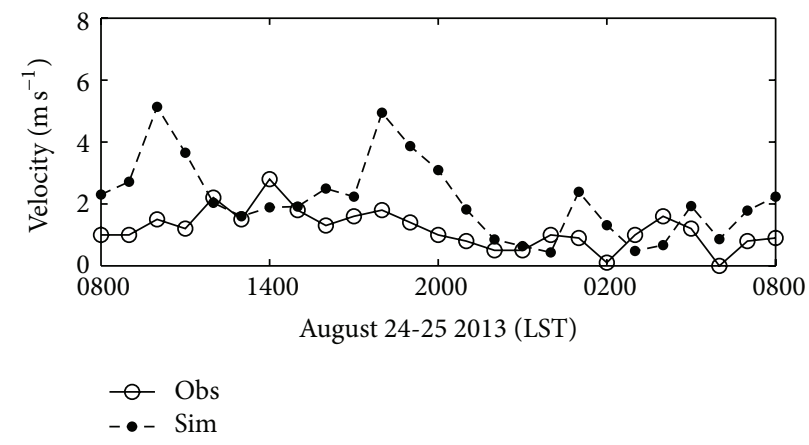

(e)

FIgURE 3: Time series of observed and simulated $10 \mathrm{~m}$ wind speed $\left(\mathrm{m} \mathrm{s}^{-1}\right)$. Please refer to Figure 2 for the descriptions of the figures.

there (Figure 6(a)). As a result, the warm upward valley breeze, northwest aloft wind, cold downward flow, and the sea breeze constitute a counterclockwise circulation viewed from the southwest in Figure 6(a), ranging from the Bohai bay to the mountains.

Comparing to the CNTL case, the onset of the sea breeze of the FLAT case is about 1200 LST (Figure 7(a)), an approximately 3-hour lag; by that moment, in the presence of the topography, the sea breeze front has already penetrated about $13 \mathrm{~km}$ inland (Figure 6(a)).

In the afternoon, the sea breeze further strengthens and continues to penetrate inland; by 1900 LST, the inland distance of the FLAT case has extended up to about $30 \mathrm{~km}$ (Figures 5(d) and 7(b)), which is the maximum penetration inland distance of FLAT case, while the inland distance of the CNTL case is up to about $60 \mathrm{~km}$ at 1900 LST (Figure 5(c)), which is twice as long as the FLAT case's. Figure 5 shows that the inland penetration process of the sea breeze strongly depends on the topography.

In the presence of the topography, the sea breeze and the thermally induced upward valley breeze can be coupled during the daytime, resulting in a stronger sea breeze circulation, and similar findings are presented by Lu and Turco [28] and Miao et al. [15].

After 1900 LST, the sea breeze of the FLAT case is going to disappear and be replaced by a land breeze (Figure 7(c)), while the sea breeze still dominates the coastline and further extends inland in the CNTL case until 2200 LST and reaches its maximum inland distance (about $110 \mathrm{~km}$ ) at $2200 \mathrm{LST}$ (Figure 6(b)).

In the CNTL experiment, at night the mountains are cooled by nocturnal radiation, which causes the air adjacent 


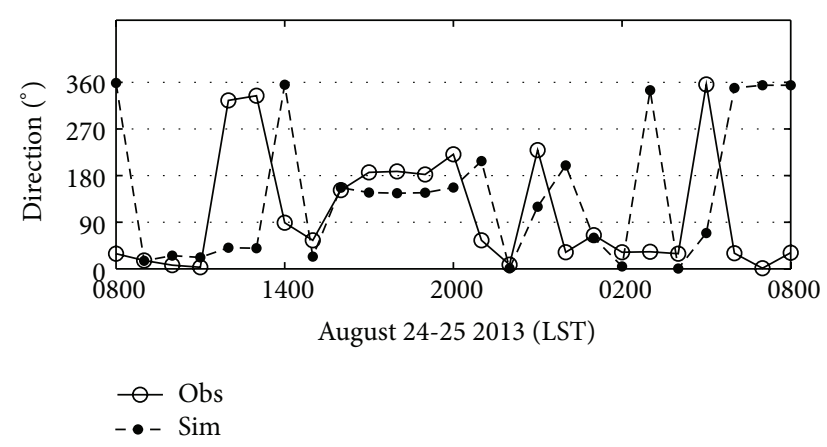

(a)

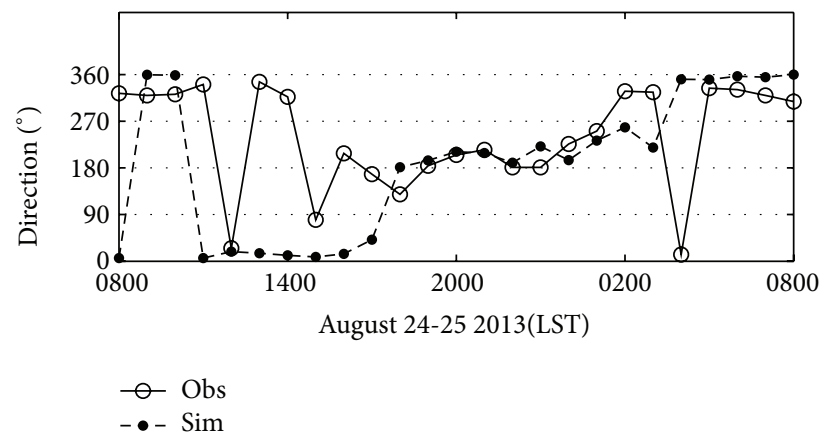

(c)

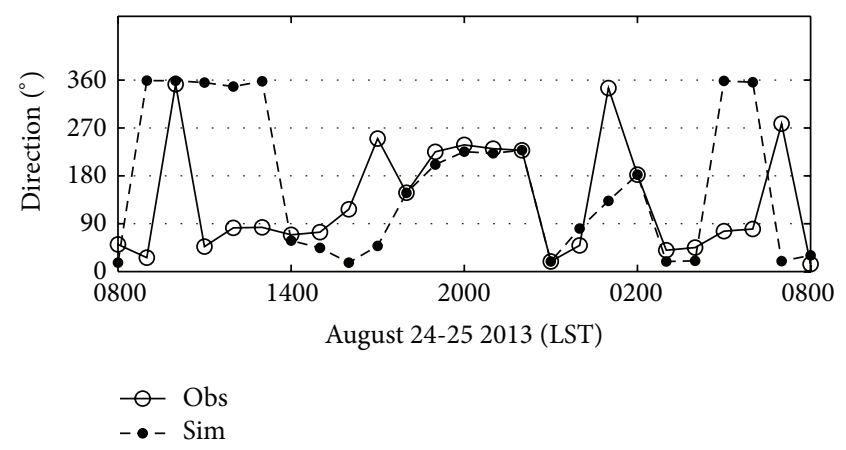

(b)

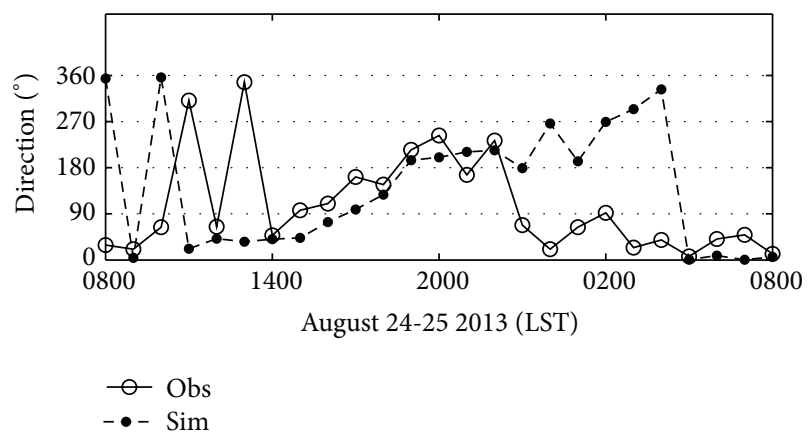

(d)

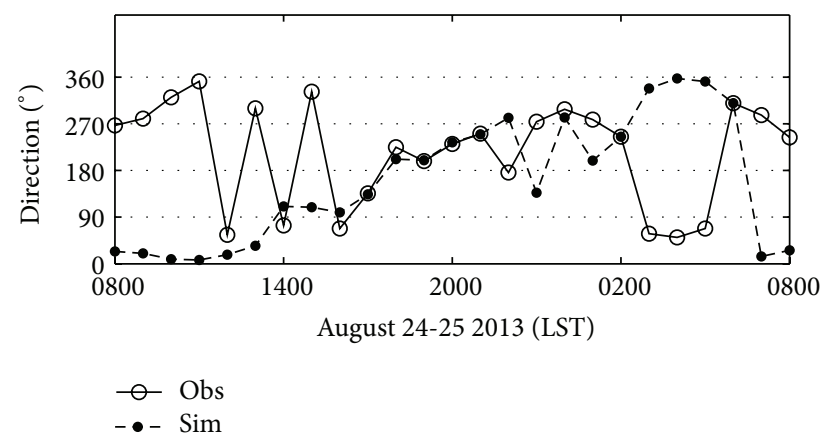

(e)

Figure 4: Time series of observed and simulated $10 \mathrm{~m}$ wind direction $\left(^{\circ}\right)$. Please refer to Figure 2 for the descriptions of the figures.

to be cooled and to flow downward to the plain (Figure 5(c)); meanwhile, the thermally induced sea breeze abates gradually. At the early night (about 2200 LST), before the onset of the land breeze, the downward mountain breeze can confront the inland sea breeze front on the south-east suburb of Beijing (about $110 \mathrm{~km}$ from the coastline) and form a convergence zone there (Figure 6(b)); the inland progress of sea breeze is slowed down by the opposite mountain breeze.

After 2200 LST, the sea breeze becomes too weak to be consistently blown from the coastline to the suburb of Beijing and is broken down at the middle of Tianjin and Langfang at 2300 LST (Figure 8(a)), about $63 \mathrm{~km}$ from the coastline, and turns into 2 substreams, that is, the seaside substream and the inland substream. The inland substream can continue to progress inland to the foot of mountains by the inertial forcing (Figures 8(a) and 8(c)). At midnight, the inland substream can reach the downtown of Beijing and disappears gradually by counteracting with the downward mountain breeze there (Figure 8(c)). Meanwhile, the seaside has substream retracted to the Tianjin areas.

After midnight, the sea breeze is going to disappear and be replaced by the land breeze at about 0200 LST. By 0400 LST, the land breeze can couple with the mountain breeze to form a clockwise circulation (viewed from the southwest), ranging from the mountains to the Bohai bay (Figure 6(c)); as a result, the land breeze circulation is strengthened.

To better evaluate the difference between the numerical experiments, some parameters of the vertical cross section along the solid line from A to B in Figure 1(b) are defined as follows.

(1) Here we define the $U$ as the horizontal wind of the vertical cross sections, and the $\mathbf{U}$ is positive value when the wind is blown from point A to point B. 


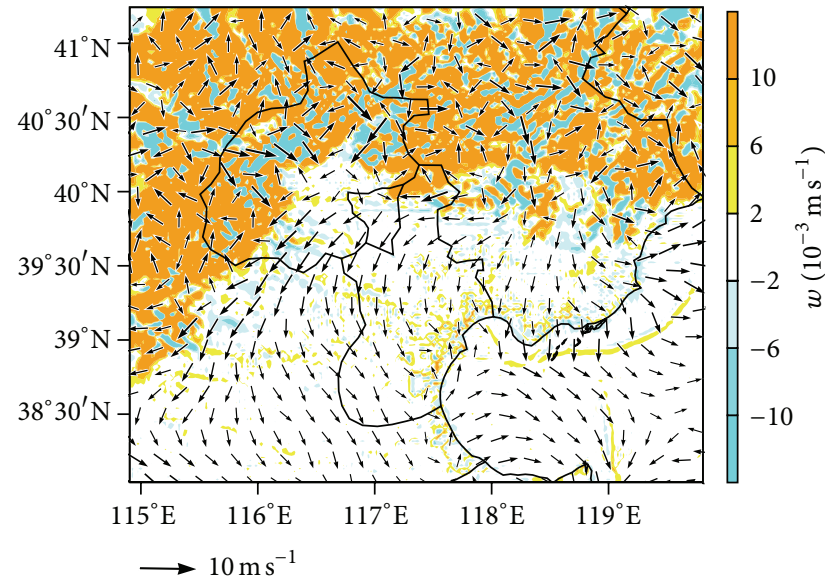

(a) 0900

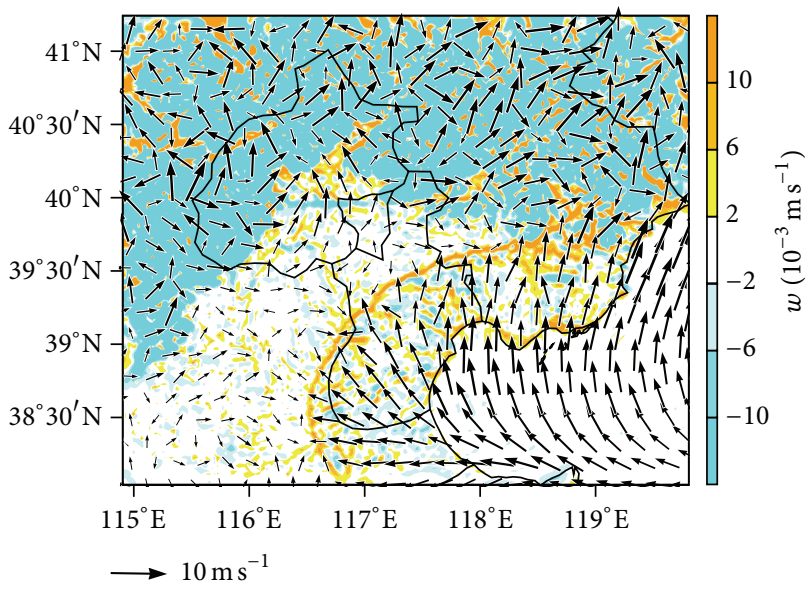

(c) 1900

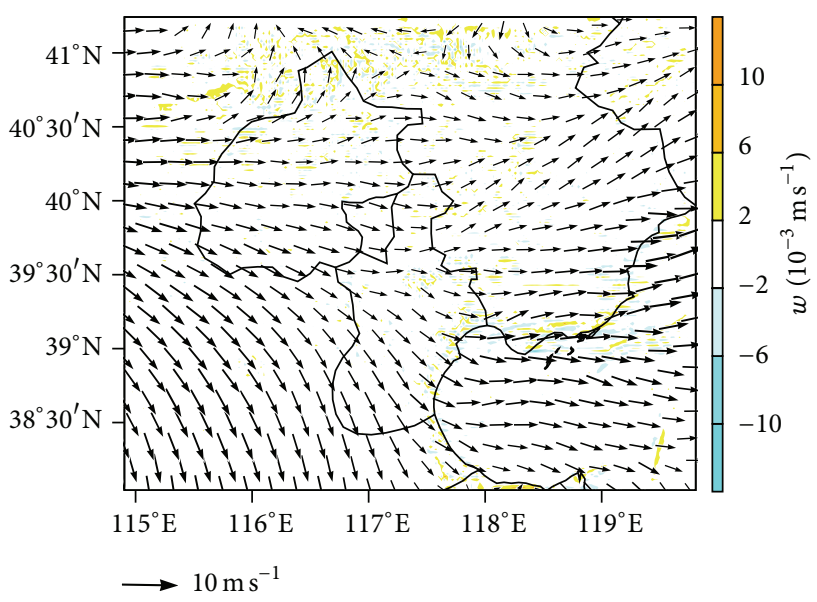

(b) 0900

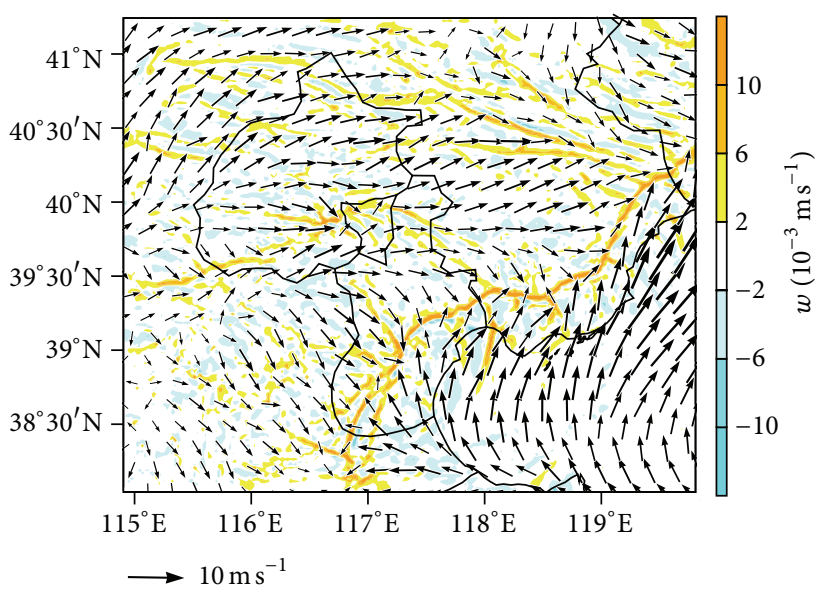

(d) 1900

Figure 5: Simulated $10 \mathrm{~m}$ wind field and the vertical wind component on the lowest vertical level at 0900 LST and 1900 LST 24 August, 2013; (a) and (c) CNTL and (b) and (d) FLAT. The location of sea breeze inland front can be indicated by the convergence zone with high vertical wind component $(w)$.

TABLE 4: Summaries of the evaluation parameters of the vertical cross section from A to B in Figure 1(b).

\begin{tabular}{|c|c|c|c|c|}
\hline & CNTL & FLAT & RURAL & REAL \\
\hline Sea breeze start time & 0800 LST & $1200 \mathrm{LST}$ & $0800 \mathrm{LST}$ & 0800 LST \\
\hline Sea breeze end time & 0200 LST & 2100 LST & 0200 LST & 0100 LST \\
\hline Maximum inland penetration distance and the time & $\begin{array}{l}110 \mathrm{~km}, \\
2200 \mathrm{LST}\end{array}$ & $\begin{array}{c}31 \mathrm{~km}, \\
1900 \mathrm{LST}\end{array}$ & $\begin{array}{l}127 \mathrm{~km}, \\
2300 \mathrm{LST}\end{array}$ & $\begin{array}{l}113 \mathrm{~km}, \\
2200 \mathrm{LST}\end{array}$ \\
\hline
\end{tabular}

(2) The inland penetration distance of the sea breeze is defined as the north-western most location that the mean $\mathbf{U}$ value of the lowest $100 \mathrm{~m}$ height is consistently positive from the coastline and the mean $w$ is positive. It is noted that, at night, when the sea breeze is separated into the seaside and inland substreams, the penetration distance of sea breeze is defined as the penetration distance of the seaside substream.

(3) The sea breeze start time is defined as the time when the mean $\mathrm{U}$ value of the lowest $100 \mathrm{~m}$ at the coastline becomes positive, while the sea breeze end time is the time when the mean $\mathbf{U}$ value there becomes negative.

The penetration process of sea breeze front is summed up in Figure 9 and Table 4. It is found that the sea breeze circulation is strengthened in the presence of the topography, with longer maximum inland penetration distance $(110 \mathrm{~km})$ and longer lasted duration of sea breeze.

In general, comparing to the FLAT experiment, the topography plays an important role in the strengthening of the SLB circulation. It is also worth noting that Beijing locates too far from the coastline to be affected by the SLB 


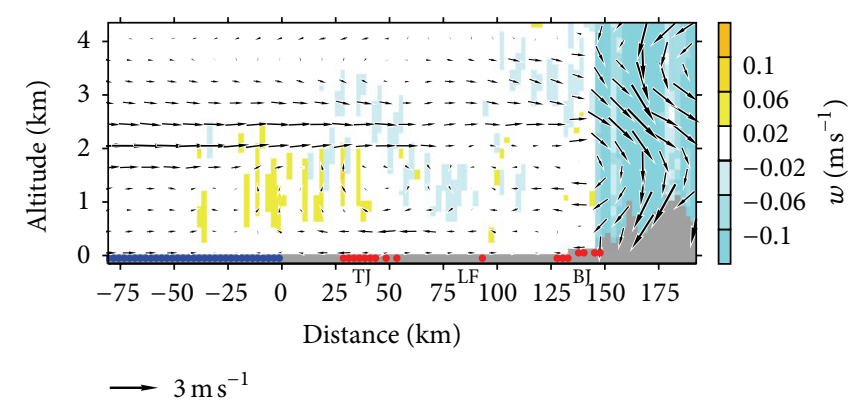

(a) 1200

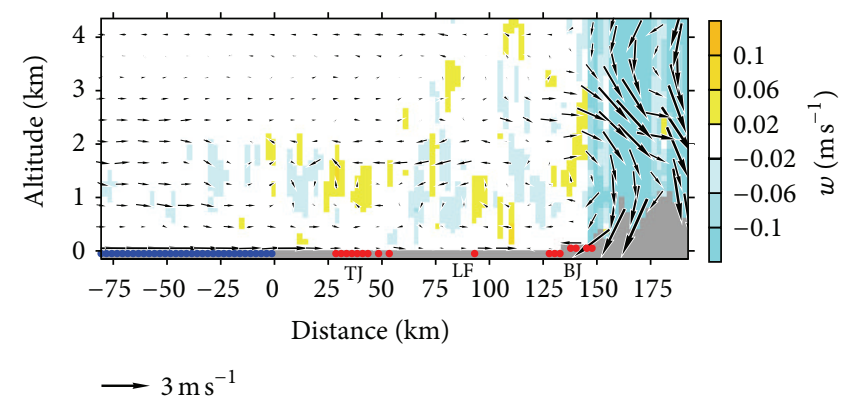

(b) 2200

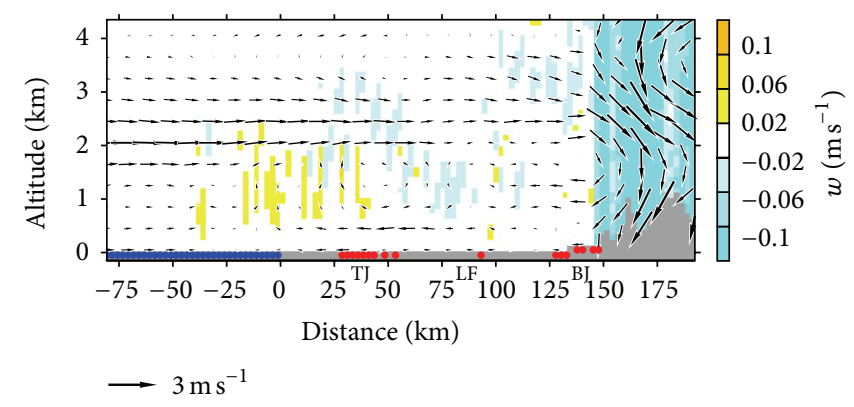

(c) 0400

FIGURE 6: Vertical cross section of simulated wind field of CNTL experiment from A to B in Figure $1(\mathrm{~b})$, with the reference point $(0,0)$ located at the border (point O in Figure 1(b)) of land and sea. (a) 1200 LST 24 August, (b) 2200 LST 24 August, and (c) 0400 LST 25 August. The urban land use grids are indicated by the red dots, while the water land uses grids that are presented by the blue dots. To plot the vector field, the $\mathbf{U}$ and $w$ have been multiplied by a factor of 0.5 and 10 , respectively, while the real value of $w$ is shown by the color shade background. The three cities from left to right are Tianjin (TJ), Langfang (LF), and Beijing (BJ), respectively.

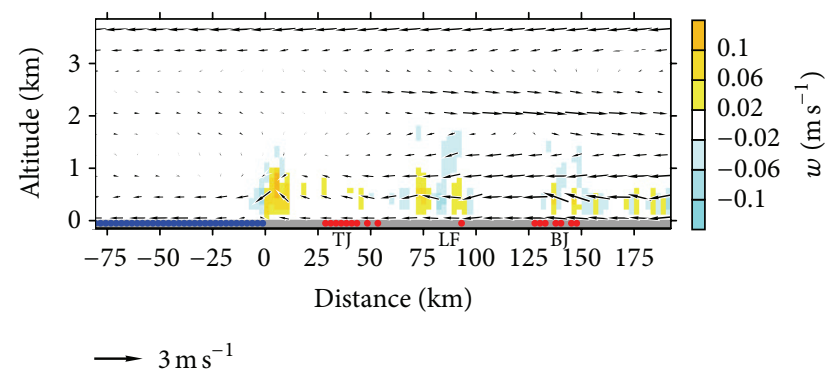

(a) 1200

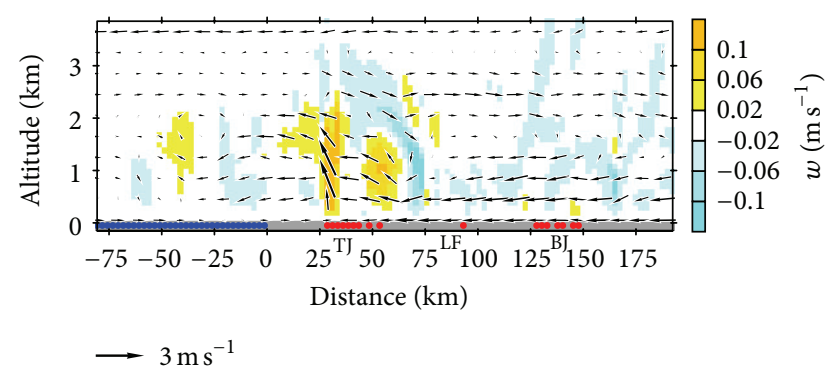

(b) 1900

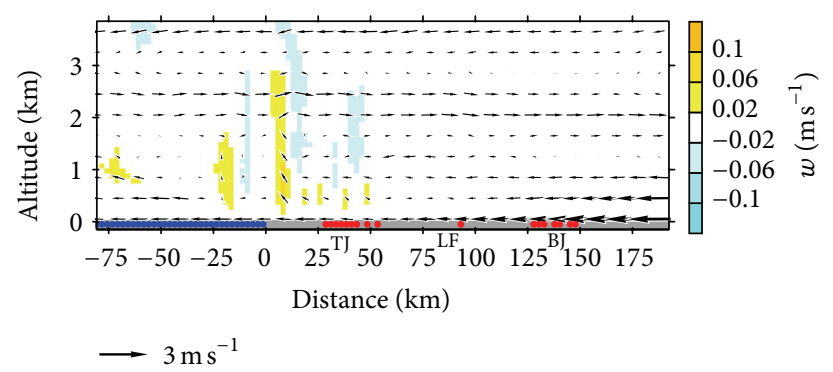

(c) 0400

Figure 7: Similar to Figure 6, but for the FLAT experiment. (a) 1200 LST 24 August, (b) 1900 LST 24 August, and (c) 0400 LST 25 August. The three cities from left to right are Tianjin (TJ), Langfang (LF), and Beijing (BJ), respectively. Please refer to Figure 6 for more details of the figure description. 


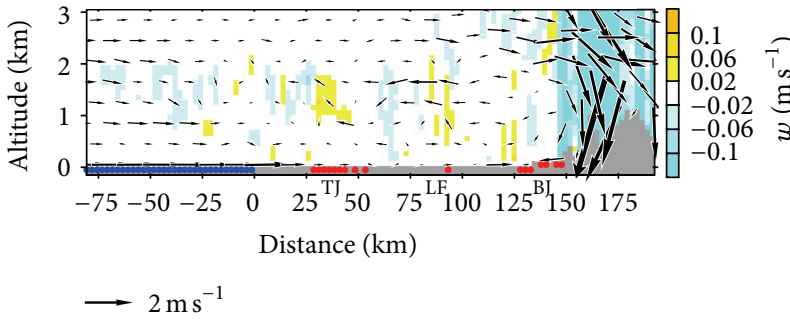

(a) 2300

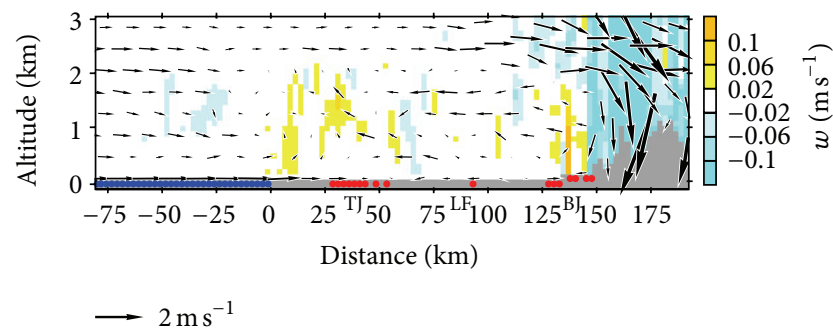

(c) 0000

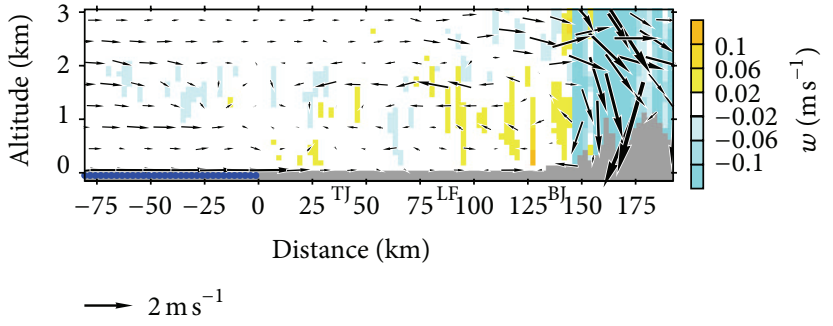

(b) 2300

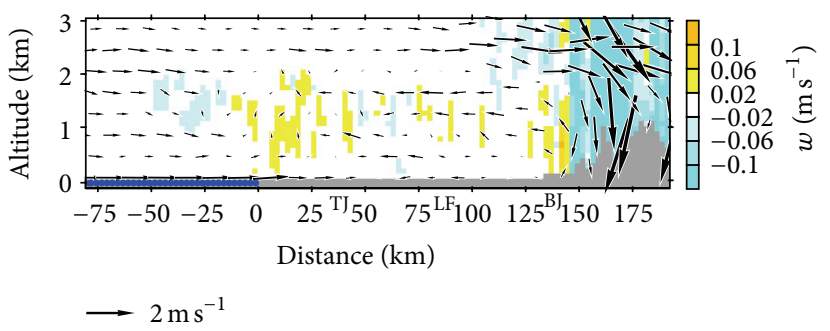

(d) 0000

FIgURE 8: Similar to Figure 6, but for the vector fields at 2300 LST 24 August and 0000 LST 25 August, (a) and (c) CNTL and (b) and (d) RURAL. The three cities from left to right are Tianjin (TJ), Langfang (LF), and Beijing (BJ), respectively. Please refer to Figure 6 for more details of the figure description.

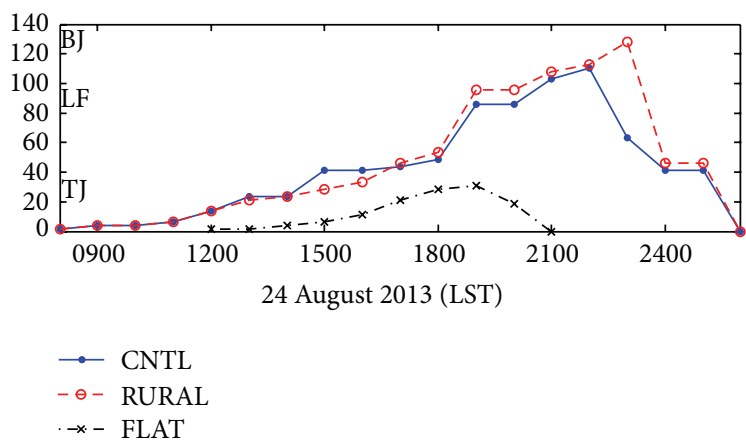

(a)

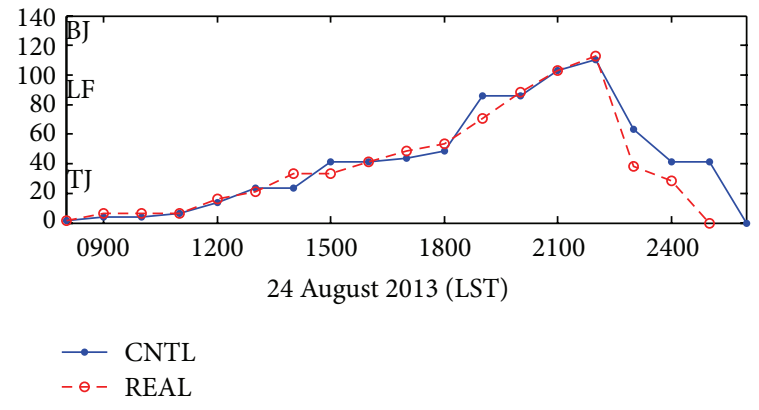

(b)

FIGURE 9: The time series of the maximum inland distance of different numerical experiments within the vertical cross section from A to B in Figure 1(b).

circulation directly, therefore, in summer Beijing area is primarily dominated by the MVB circulation [12, 29]; and only the soft inland sub-stream of the sea breeze can reach the downtown of Beijing at midnight, when it is going to disappear.

\subsection{Effects of the Urbanization on the Local Atmospheric} Circulation. The urban areas are the anthropogenic sources of heat and pollution. And the urban areas are usually covered by a large percentage of asphalt and concrete, whose land surface is dry and water-proof, with high heat capacities; the urban areas convert and store incoming radiation as sensible heat better than the surrounding natural areas. Thus, the surface-layer air in the cities is generally warmer than that of rural areas, and the horizontal temperature variations induce the UHI circulation between the urban and rural areas. In addition, the buildings within the cities can increase the surface drag and wake turbulence, and the buildings act to reduce surface-layer wind speed $[30,31]$.

To investigate the effects of the urbanization on the local atmospheric circulation, the RURAL experiment was performed by changing all the urban grids (Figure 1(b)) to the cropland grids. The simulated wind fields of the CNTL and RURAL experiments at 2000 LST are demonstrated in Figure 10. At $2000 \mathrm{LST}$, the mountain areas are dominated by the cold downward mountain breeze, while the sea breeze still continues to progress inland. It is found that the simulated wind field of RURAL experiment is similar to that of CNTL experiment, and the sea breeze fronts of these two experiments are almost the same, except for the slight lags at some place along the sea breeze front (Figure 10(c)).

The vertical cross sections of the CNTL and RURAL experiments at 1400 LST are shown in Figure 11. It is found 


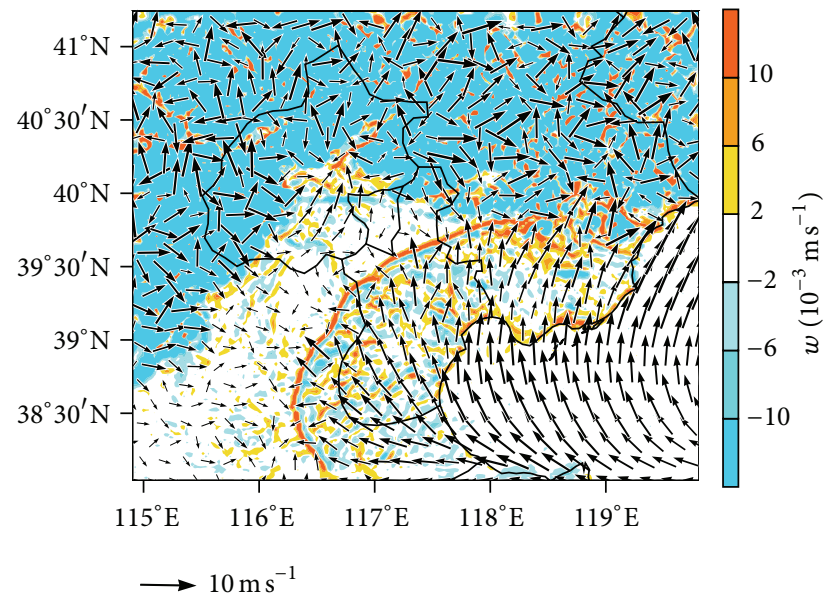

(a)

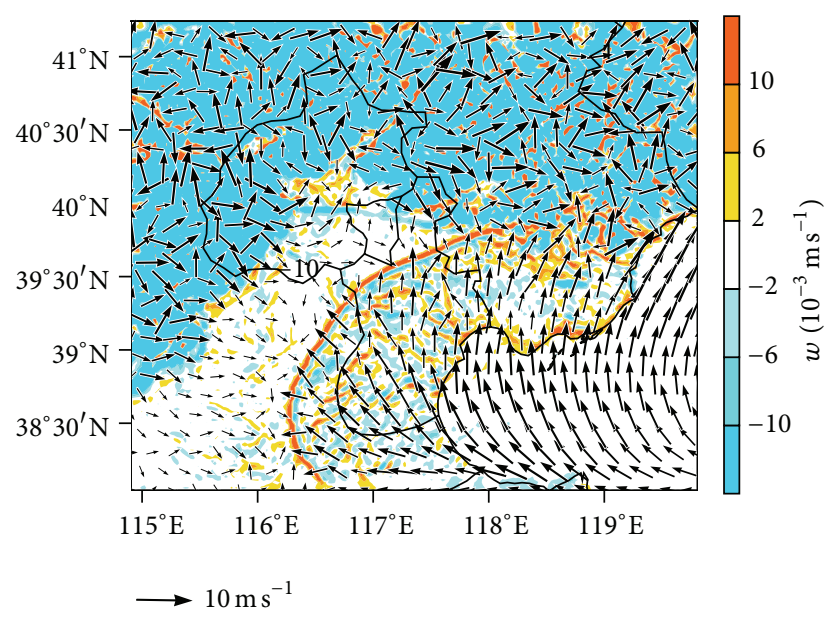

(b)

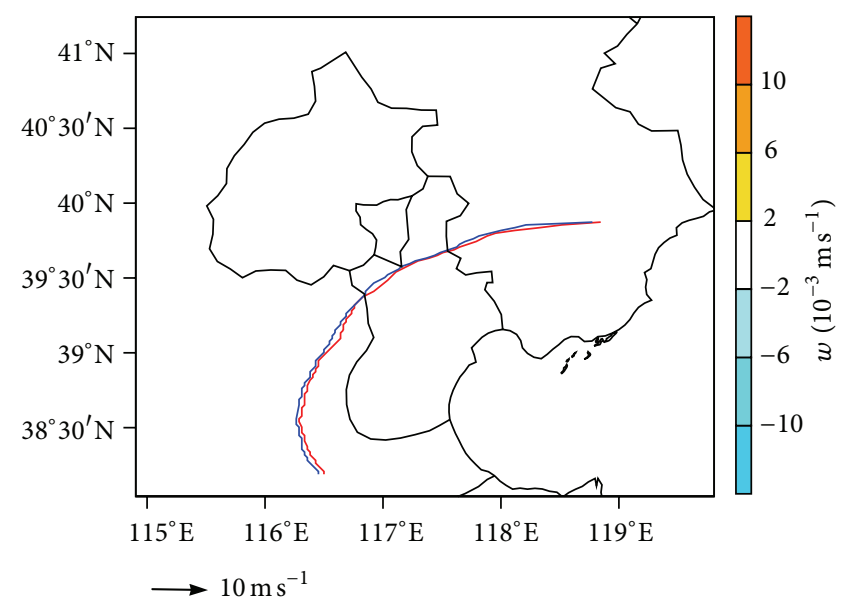

(c)

Figure 10: Simulated $10 \mathrm{~m}$ wind field and the vertical wind component on the lowest vertical level at 2000 LST 24 August, 2013 ; (a) CNTL and (b) RURAL. The locations of sea breeze inland fronts of the CNTL (red) and RURAL (blue) experiments are indicated by the solid line in $(\mathrm{c})$.

that the general local atmospheric circulations of the RURAL experiment and CNTL experiment are quite similar, except for the upward motions imposed over the urban grids (Figures 11(c) and 12(c)). These upward motions indicate the UHI circulations over the urban areas (i.e., Beijing, Langfang, and Tianjin).

In the perspective of the inland penetration process of the sea breeze (Figure 9(a)), before 1400 LST there is no significant difference between the CNTL and RURAL experiments. It is because, before $1400 \mathrm{LST}$, the sea breeze front is still out of the effective radius of the Tianjin UHI circulation.

By 1400 LST, when the sea breeze front has progressed inland to the south-east suburb of Tianjin, about $23 \mathrm{~km}$ from the coastline, a strong counterclockwise UHI circulation viewed from the southwest (Figure 11(c)) imposed on the sea breeze circulation; the UHI circulation is ranged from the suburb to the downtown of Tianjin and consistent with the sea breeze circulation. As a result, the sea breeze circulation is strengthened by the UHI circulation. Therefore, after 1400 LST the sea breeze inland front moves faster in the presence of Tianjin and reaches the downtown of Tianjin at 1500 LST, about $41 \mathrm{~km}$ from the coastline (Figure 9(a)).

However, when the sea breeze front moves further through the densely built-up areas of Tianjin, the inland movement of the sea breeze front is slower by the higher surface drag there; thus, after 1500 LST, the inland movement of the sea breeze front of the CNTL experiment becomes slower than that of the RURAL experiment (Figure 9(a)). By 1800 LST, the CNTL experiment's sea breeze front has already lagged behind the RURAL's about $5 \mathrm{~km}$ and lags more at 1900 LST.

It is worth noting that, after $2000 \mathrm{LST}$, the difference between the inland distances of the CNTL and RURAL experiments becomes smaller, and the CNTL experiment's sea breeze front catches up with the RURAL's at about 2200 LST (Figure 9(a)). This phenomenon can be explained by the effects of the urban areas (Beijing) on the mountain 


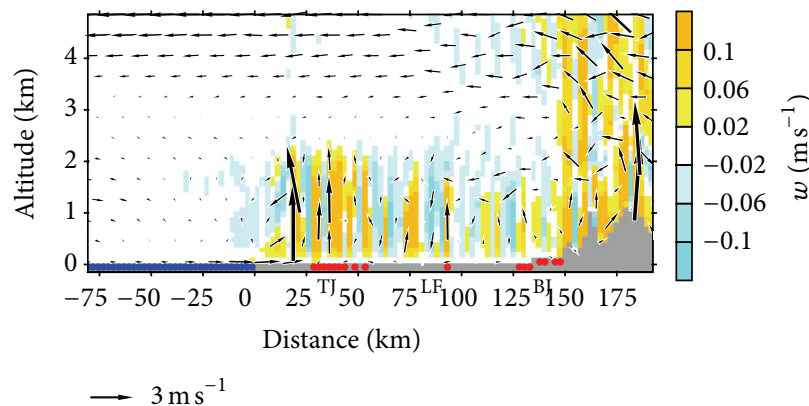

(a) CNTL

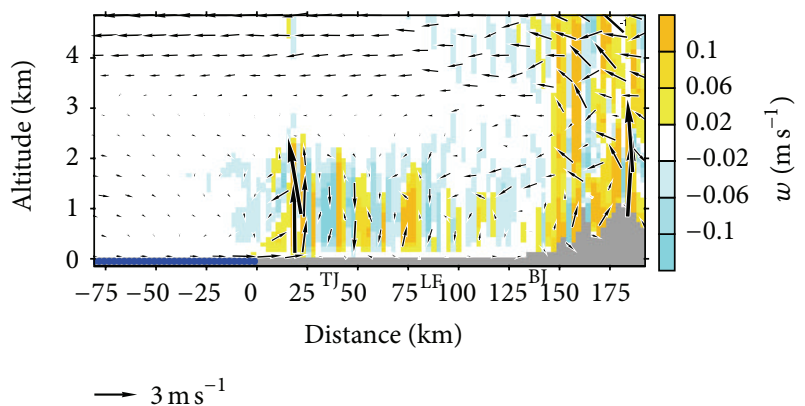

(b) RURAL

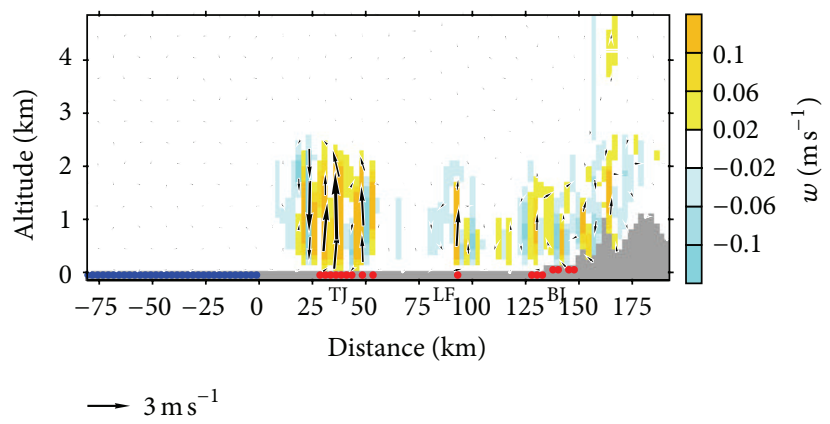

(c) CNTL-RURAL

FIGURE 11: Vertical cross section of simulated wind filed from A to B in Figure 1(b) at 1400 LST 24 August, (a) CNTL, (b) RURAL, and (c) CNTL-RURAL. The three cities from left to right are Tianjin (TJ), Langfang (LF), and Beijing (BJ), respectively. Please refer to Figure 6 for more details of the figure description.

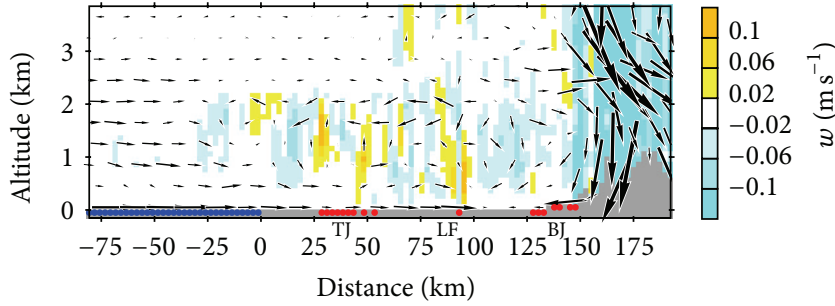

$\longrightarrow 2 \mathrm{~ms}^{-1}$

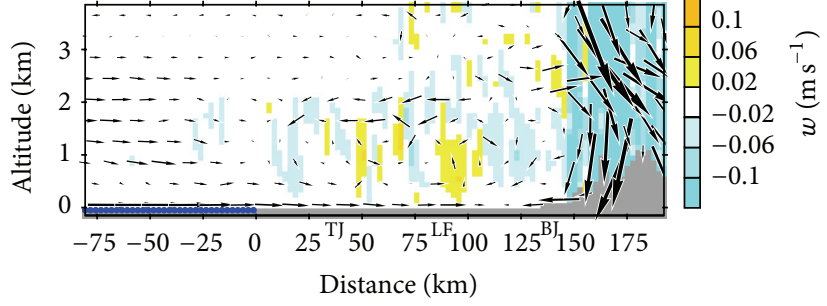

$\longrightarrow 2 \mathrm{~ms}^{-1}$

(b) RURAL

(a) CNTL

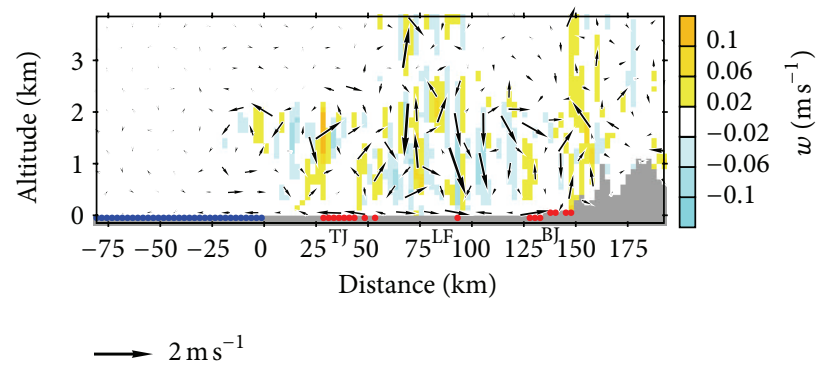

(c) CNTL-RURAL

Figure 12: Similar to Figure 11, but for the vector fields at 2100 LST 24 August, (a) CNTL, (b) RURAL, and (c) CNTL-RURAL. The three cities from left to right are Tianjin (TJ), Langfang (LF), and Beijing (BJ), respectively. Please refer to Figure 11 for more details of the figure description. 


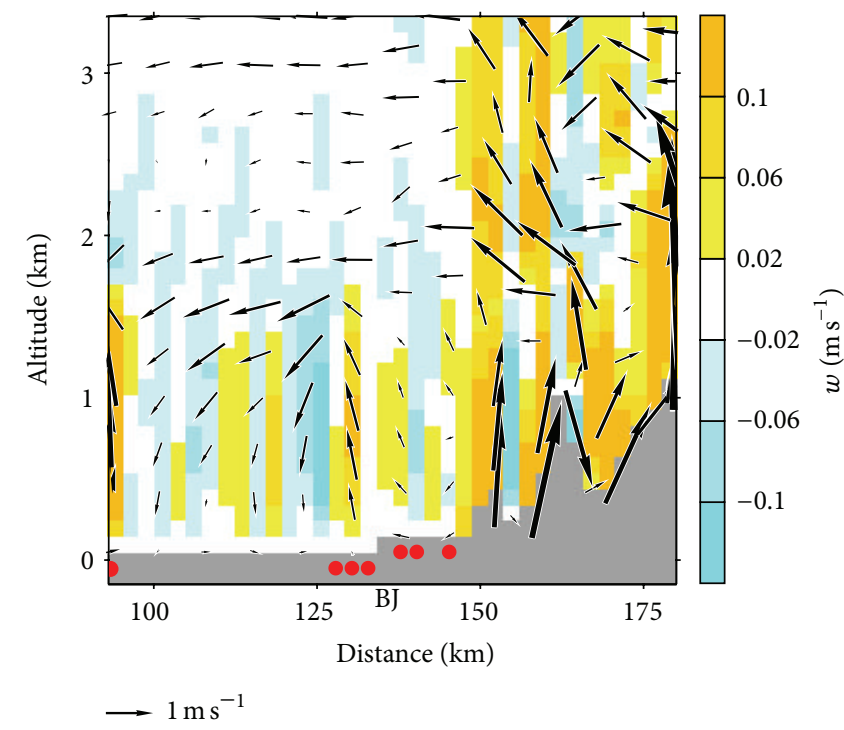

(a) 1500

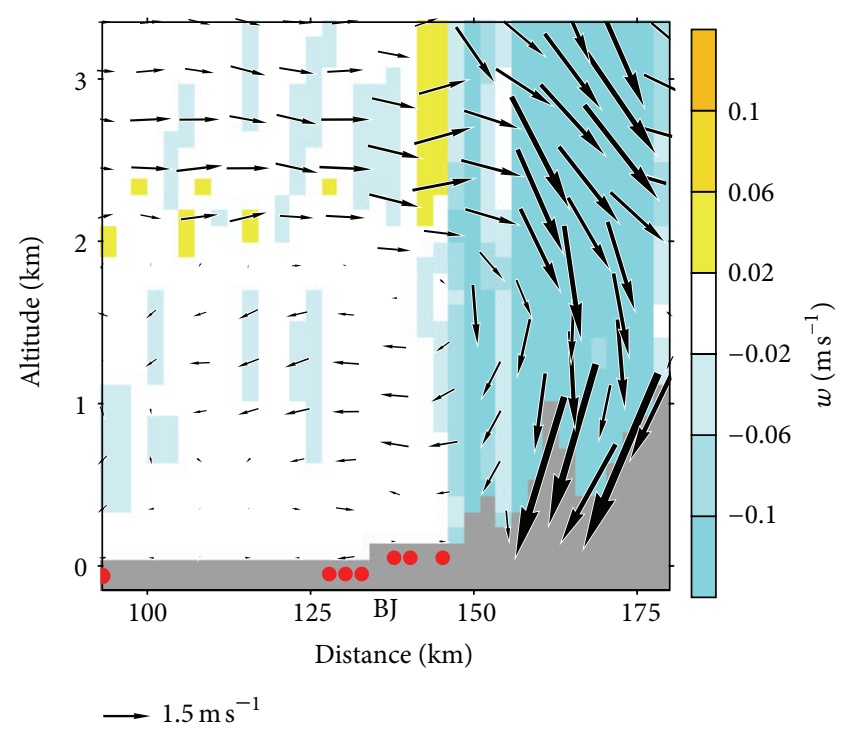

(b) 0200

Figure 13: Vertical fields over Beijing in the CNTL experiment at (a) 1500 LST 24 August and (b) 0200 LST 25 August. Please refer to Figure 6 for more details of the figure description.

breeze circulation. After 2000 LST, when the mountain breeze dominates the plain regions, as we discussed in Section 3.2, the inland progress of sea breeze is slowed down by the opposite mountain breeze; the presence of Beijing increases the surface drag and weakens the mountain breeze circulation and indirectly helped the sea breeze to extend further inland by imposing an opposite wind near the surface (Figure 12(c)).

Meanwhile, the inland process of sea breeze is also slowed down slightly by Tianjin because of the high surface drag, which is imposed on an opposite wind of sea breeze near the surface (Figure 12(c)). Under this drag effect, the sea breeze is broken into 2 substreams earlier at about 2300 LST in the CNTL experiment (Figures 8(a) and 9(a)). In contrast, the sea breeze front can consistently extend to the foot of mountains at 2300 LST (Figure $8(\mathrm{~b})$ ) in absence of the cities, about $127 \mathrm{~km}$ from the coastline, and then turns into 2 substreams about midnight (Figure 8(d)).

In addition, since Beijing is located at the foot of the mountains, the development of the UHI circulation there is strongly affected by the topographic forcing. In the afternoon, the north-west part of Beijing, more close to the mountains, is dominated by the upward valley breeze, where the UHI is inhibited, while the UHI circulation is able to fully develop at the other side of Beijing. It is noted that the return aloft antivalley wind can flow over the urban areas of Beijing and descend at the south-east suburb and then participates into and strengthens the UHI circulation over the south-east part of Beijing (Figure 13(a)). At night, the UHI circulation over Beijing is hidden in the stronger downward mountain breeze circulations (Figure 13(b)).

In general, the presence of cities cannot change the general state of the SLB circulation and the MVB circulation but acts to modify these local circulations slightly. And the development of the UHI circulation is strongly influenced by the nearby MVB circulation and SLB circulation.

3.4. The Schematic Circulations of the Idealized Simulation. In this section, the schematic circulations of the idealized CNTL experiment are summed up firstly, and then the simulations of REAL experiment are compared with the schematic circulations to find out the effects of the weak synoptic system. The schematic diagrams of the local idealized circulations at three moments are presented in Figure 14.

Because of the complexity of topography and the heterogeneity of land use distribution of the $\mathrm{BTH}$ region, in the daytime there may exist multiscale local atmospheric circulation (Figure 14(a)). As discussed in Section 3.2, in the afternoon, the valley breeze circulation can couple with the sea breeze circulation to form a counterclockwise circulation viewed from the southwest (Figures 14(a) and 11(a)), ranging from the coastline to the mountains, and the vertical and horizontal dimensions are $3.5 \mathrm{~km}$ and $150 \mathrm{~km}$, respectively. At 1400 LST, it is worth noting that the aloft antivalley wind also exists at the altitude of $2 \mathrm{~km}$, which cannot reach the coastline, but subsides at the suburb of Beijing (about $120 \mathrm{~km}$ away from the coastline) and then returns to the mountain areas. As a result, the UHI circulation over the south-east part of Beijing is strengthened. The similar phenomenon is also found in Langfang. Between Tianjin and Langfang, there is another land-land circulation located at the southeast of Langfang (about $70 \mathrm{~km}$ away from the coastline); the circulation is developed over the crop/woodland mosaic land use category, whose albedo is lower than the surrounded grids'. 
Meanwhile, the Tianjin area is dominated by the strong counterclockwise sea breeze circulation viewed from the southwest, accompanied by a weak clockwise circulation, which is a secondary circulation driven by the sea breeze circulation and the land-land circulation. In the idealized experiment (CNTL), these multiscale circulations are established at about 1400 LST and are able to sustain to the sunset moment (about 1900 LST).

Comparing to the daytime circulations, the circulations at night are simpler. After sunset, the upward valley breeze is going to disappear and be replaced by the downward mountain breeze, while the sea breeze front continues to progress further inland. At the south-east of Beijing, a convergence zone is formed by the interaction of the mountain breeze circulation and the sea breeze circulation (Figure 14(b)). The presence of the mountain breeze circulation can slow down the inland progress of sea breeze.

After midnight, as the sea breeze is replaced by the land breeze, a large clockwise circulation (viewed from the southwest) consisted of the land breeze circulation and the mountain breeze circulations (Figure 14(c)), ranging from the coastline to the mountains.

The schematic circulations are got from the idealized simulation, which is only driven by the local thermal effects without external influences. To examine the representativeness of these schematic circulations, the REAL experiment was performed by using the realistic initial and boundary conditions. During the simulation period, the BTH region is dominated by a high pressure synoptic system. The vertical cross section of simulated wind fields in the REAL experiment is demonstrated in Figure 15.

Comparing with the schematic circulation at 1400 LST, it is found that the daytime multiscale circulation revealed in the idealized CNTL experiment (Figures 14(a) and 11(a)) also exists in the REAL experiment (Figure 15(a)), expect that the upward motions over the mountains and the urban areas are weaker and the west aloft wind is stronger. The weakening of the upward motions may be caused by masking effect of the cloud, which is avoided in the idealized experiment.

At night, when the mountain breeze blows, the circulations in the REAL experiment are almost the same as the CNTL's (Figures 14(b) and 6(b)), except for the strengthening of the aloft antimountain wind (Figure 15(b)). After midnight, the large coupled clockwise circulation (viewed from the southwest) can also be found in the REAL experiment (Figure 15(c)).

The start time, end time, and maximum inland distance of the sea breeze of the REAL experiment are also given in Table 4 and Figure 9(b). It is found that under the weak synoptic condition, the sea breeze can also penetrate inland more than $110 \mathrm{~km}$, and the penetration process is almost the same as that of the idealized experiment, except that the sea breeze of the REAL experiment disappears an hour earlier.

In short, under the weak synoptic condition, the idealized local thermally induced circulations are slightly modified; the multiscale structure and the coupled circulations can exist in the real situations. However, in some real situations, the ambient synoptic forcing can modify or even eliminate these local atmospheric circulations.

\section{Conclusions}

In this study, the effects of the topography and urbanization on the local thermally induced circulations over the TBH region were investigated by WRF. The local atmospheric circulations of the summer months were firstly investigated by using the idealized initial and boundary conditions to avoid the external influences, and then the realistic circulations under weak synoptic condition were studied.

It is found that, in the summer day time, when upward valley breeze blows, the topography plays a role in the strengthening of the sea breeze circulations; after sunset, when the downward mountain breeze dominates over the mountain areas, the inland progress of sea breeze is slowed down by the opposite mountain breeze; after midnight, when the sea breeze circulation is replaced by the land breeze circulation, the mountain breeze circulation can couple with the land breeze to form a large circulation ranging from the coastline to the mountains. Because of the complexity of topography and the heterogeneity of land use distribution of the BTH region, in the daytime multiscale local atmospheric circulations may exist and interact at the same time (Figure 14(a)).

The presence of cities cannot change the general state of the SLB circulation and MVB circulation but acts to modify these local circulations slightly. The urban areas play a role in the warming of the air adjacent to the surface and increase the surface drag; the modifications of the local circulations are the results of the warming and drag effects. In the earlier afternoon, the inland process of sea breeze is strengthened in presence of Tianjin by the thermally induced UHI circulation; however, when the sea breeze front penetrates through the built-up areas of Tianjin, the inland process is slowed down by the drag effect. And, after sunset, when the downward mountain breeze appears, the presence of Beijing can indirectly strengthen the inland process by weakening the opposite mountain breeze.

Meanwhile, the development of the UHI circulation is also strongly influenced by the MVB circulation and the SLB circulation. In the daytime, the UHI circulation over Beijing area is asymmetric under the influences of the topography.

Comparing the realistic simulation with the idealized simulation, it is found that, under the weak synoptic condition, the idealized local thermally induced circulations are slightly modified. However, in some real situations, the ambient synoptic forcing can modify or even eliminate these local atmospheric circulations.

Since the local atmospheric circulations are driven by the thermal forcing, the characteristics of the local circulations varies in different seasons; therefore, further study needs to be done to understand the different seasons' circulations.

Finally, it should be pointed out that this study is just a preliminary numerical work to understand the complex interactions of the local atmospheric circulations over BTH region. More studies of field works and numerical experiments are therefore needed to fully understand these circulations and their effects on the pollution events. 


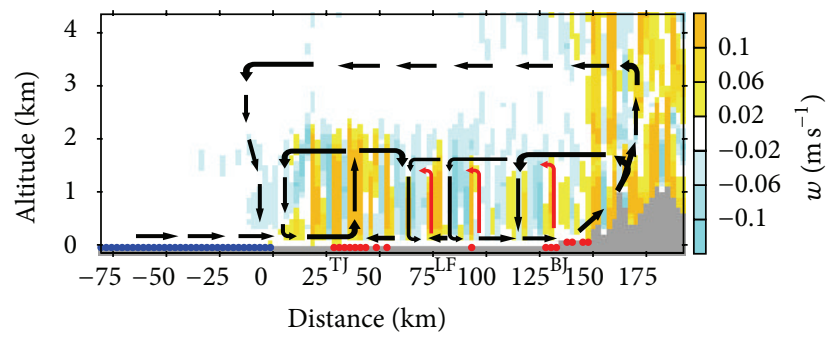

(a) 1400

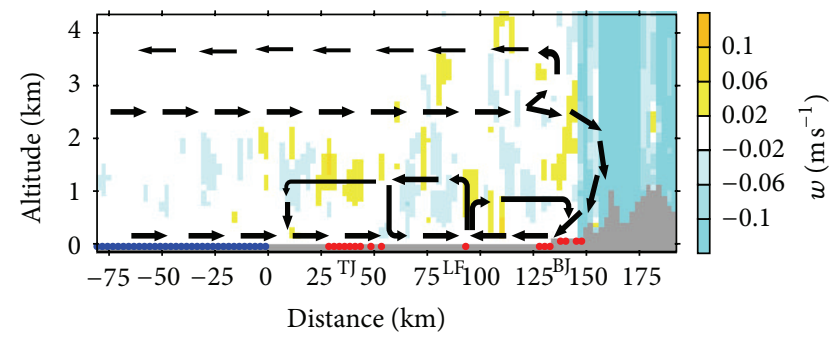

(b) 2200

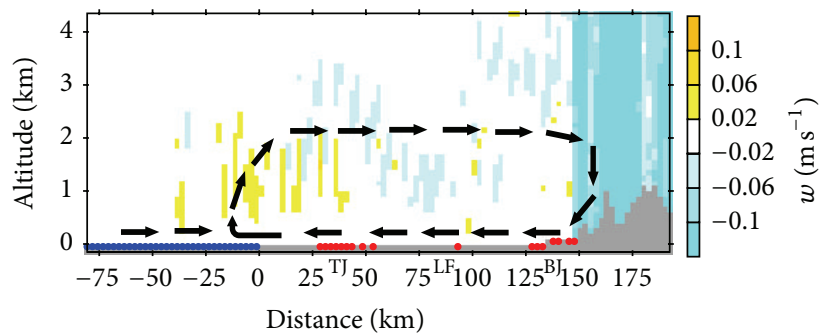

(c) 0400

Figure 14: The schematic representation of the local circulations in the CNTL experiment, (a) 1400 LST 24 August, (b) 2200 LST 24 August, and (c) 0400 LST 25 August; the three cities from left to right are Tianjin (TJ), Langfang (LF), and Beijing (BJ), respectively. Please refer to Figure 6 for more details of the figure description. At 1400 LST, except for the strong SLB circulation and MVB circulation, the upward motions of the smaller scale local circulations (i.e., UHI circulation) were indicated by the red arrows. (a) represents Figure 11(a) and (b) and (c) represent Figures 6(b) and 6(c), respectively.

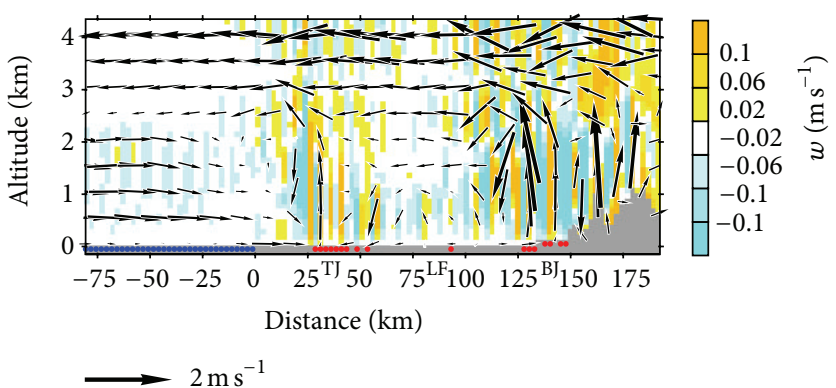

(a) 1400

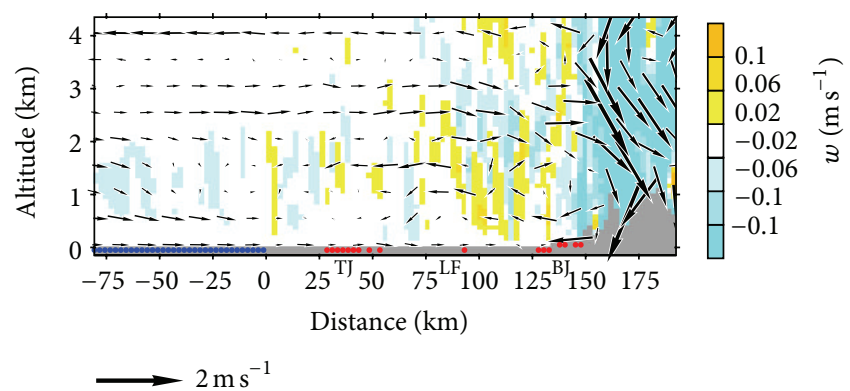

(b) 2200

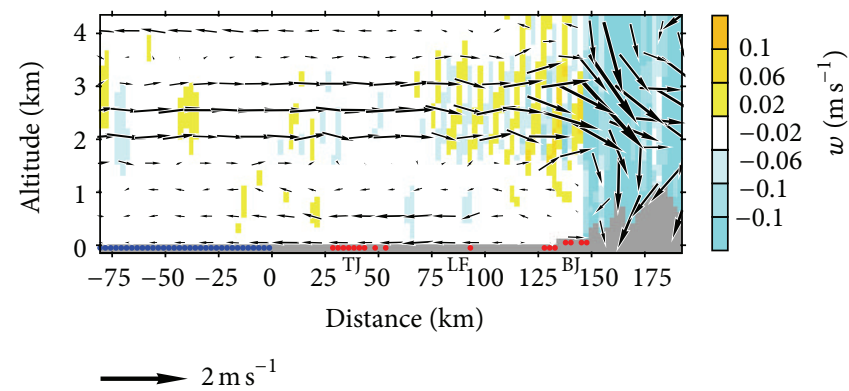

(c) 0400

FIGURE 15: Vertical cross section of simulated wind filed of the REAL experiment, (a) 1400 LST 24 August, (b) 2200 LST 24 August, and (c) 0400 LST 25 August; the three cities from left to right are Tianjin (TJ), Langfang (LF), and Beijing (BJ), respectively. Please refer to Figure 6 for more details of the figure description. 


\section{Conflict of Interests}

The authors declare that there is no conflict of interests regarding the publication of this paper.

\section{Acknowledgment}

This work was supported by the National Natural Science Foundation of China (Grant no. 41175004).

\section{References}

[1] Z. Yan, Z. Li, Q. Li et al., "Effects of site change and urbanization in the Beijing temperature series 1977-2006," International Journal of Climatology, vol. 30, pp. 1226-1234, 2006.

[2] Y. Miao, Y. Liu, Y. Dai et al., "Impact of urbanization on boundary layer structure in Beijing," Climate Change, vol. 120, pp. 123-136, 2013.

[3] S. Miao, F. Chen, M. A. LeMone, M. Tewari, Q. Li, and Y. Wang, "An observational and modeling study of characteristics of urban heat island and boundary layer structures in Beijing," Journal of Applied Meteorology and Climatology, vol. 48, no. 3, pp. 484-501, 2009.

[4] N. L. Seaman, "Meteorological modeling for air-quality assessments," Atmospheric Environment, vol. 34, no. 12-14, pp. 22312259, 2000 .

[5] W. M. Angevine, M. Tjernström, and M. Žagar, "Modeling of the coastal boundary layer and pollutant transport in New England," Journal of Applied Meteorology and Climatology, vol. 45, no. 1, pp. 137-154, 2006.

[6] A. Lemonsu, S. Bastin, V. Masson, and P. Drobinski, "Vertical structure of the urban boundary layer over Marseille under seabreeze conditions," Boundary-Layer Meteorology, vol. 118, no. 3, pp. 477-501, 2006.

[7] H. Liu, J. C. L. Chan, and A. Y. S. Cheng, "Internal boundary layer structure under sea-breeze conditions in Hong Kong," Atmospheric Environment, vol. 35, no. 4, pp. 683-692, 2001.

[8] G. Baumbach and U. Vogt, "Experimental determination of the effect of mountain-valley breeze circulation on air pollution in the vicinity of Freiburg," Atmospheric Environment, vol. 33, no. 24-25, pp. 4019-4027, 1999.

[9] Y. Chen, C. Zhao, Q. Zhang, Z. Deng, M. Huang, and X. $\mathrm{Ma}$, "Aircraft study of Mountain Chimney effect of Beijing, China," Journal of Geophysical Research, vol. 114, no. 8, Article ID D08306, 2009.

[10] T. Wang, A. Ding, J. Gao, and W. S. Wu, "Strong ozone production in urban plumes from Beijing, China," Geophysical Research Letters, vol. 33, no. 21, Article ID L21806, 2006.

[11] J. C. F. Lo, A. K. H. Lau, J. C. H. Fung, and F. Chen, "Investigation of enhanced cross-city transport and trapping of air pollutants by coastal and urban land-sea breeze circulations," Journal of Geophysical Research D: Atmospheres, vol. 111, Article ID D14104, 2006.

[12] S. Liu, Z. Liu, J. Li et al., "Numerical simulation for the coupling effect of local atmospheric circulations over the area of Beijing, Tianjin and Hebei Province," Science in China D: Earth Sciences, vol. 52, no. 3, pp. 382-392, 2009.

[13] J. C. F. Lo, A. K. H. Lau, F. Chen, J. C. H. Fung, and K. K. M. Leung, "Urban modification in a mesoscale model and the effects on the local circulation in the Pearl River Delta Region," Journal of Applied Meteorology and Climatology, vol. 46, no. 4, pp. 457-476, 2007.
[14] E. D. Freitas, C. M. Rozoff, W. R. Cotton, and P. L. S. Dias, "Interactions of an urban heat island and sea-breeze circulations during winter over the metropolitan area of São Paulo, Brazil," Boundary-Layer Meteorology, vol. 122, no. 1, pp. 43-65, 2007.

[15] J.-F. Miao, L. J. M. Kroon, J. Vilà-Guerau de Arellano, and A. A. M. Holtslag, "Impacts of topography and land degradation on the sea breeze over eastern Spain," Meteorology and Atmospheric Physics, vol. 84, no. 3-4, pp. 157-170, 2003.

[16] T. Nitis, D. Kitsiou, Z. B. Klaić, M. T. Prtenjak, and N. Moussiopoulos, "The effects of basic flow and topography on the development of the sea breeze over a complex coastal environment," Quarterly Journal of the Royal Meteorological Society, vol. 131, no. 605, pp. 305-327, 2005.

[17] M. Tao, L. Chen, L. Su, and J. Tao, "Satellite observation of regional haze pollution over the North China Plain," Journal of Geophysical Research, vol. 117, no. 12, Article ID D12203, 2012.

[18] X. G. Liu, J. Li, Y. Qu et al., "Formation and evolution mechanism of regional haze: a case study in the megacity Beijing, China," Atmospheric Chemistry and Physics, vol. 13, no. 9, pp. 4501-4514, 2013.

[19] Y. Sun, Q. Jiang, Z. Wang et al., "Investigation of the sources and evolution processes of severe haze pollution in Beijing in January 2013," Journal of Geophysical Research, vol. 119, no. 7, pp. 4380-4398, 2014.

[20] S.-Y. Hong, J. Dudhia, and S.-H. Chen, "A revised approach to ice microphysical processes for the bulk parameterization of clouds and precipitation," Monthly Weather Review, vol. 132, no. 1, pp. 103-120, 2004.

[21] M. J. Iacono, J. S. Delamere, E. J. Mlawer, M. W. Shephard, S. A. Clough, and W. D. Collins, "Radiative forcing by long-lived greenhouse gases: calculations with the AER radiative transfer models," Journal of Geophysical Research D: Atmospheres, vol. 113, no. 13, Article ID D13103, 2008.

[22] Y. Noh, W. G. Cheon, S. Y. Hong, and S. Raasch, "Improvement of the K-profile model for the planetary boundary layer based on large eddy simulation data," Boundary-Layer Meteorology, vol. 107, no. 2, pp. 401-427, 2003.

[23] F. Chen and J. Dudhia, "Coupling and advanced land surfacehydrology model with the Penn State-NCAR MM5 modeling system. Part I: model implementation and sensitivity," Monthly Weather Review, vol. 129, no. 4, pp. 569-585, 2001.

[24] H. Kusaka and F. Kimura, "Coupling a single-layer urban canopy model with a simple atmospheric model: impact on urban heat island simulation for an idealized case," Journal of the Meteorological Society of Japan, vol. 82, no. 1, pp. 67-80, 2004.

[25] H. Kusaka, H. Kondo, Y. Kikegawa, and F. Kimura, "A simple single-layer urban canopy model for atmospheric models: comparison with multi-layer and slab models," Boundary-Layer Meteorology, vol. 101, no. 3, pp. 329-358, 2001.

[26] J. Wang, J. Feng, Z. Yan, Y. Hu, and G. Jia, "Nested highresolution modeling of the impact of urbanization on regional climate in three vast urban agglomerations in China," Journal of Geophysical Research, vol. 117, no. 21, Article ID D21103, 2012.

[27] S. Bontemps, P. Defourny, E. V. Bogaert et al., "GLOBCOVER 2009-Products Description and Validation Report," Ionia ESA, 2011, http://due.esrin.esa.int/.

[28] R. Lu and R. P. Turco, "Air pollutant transport in a coastal environment-II. Three-dimensional simulations over Los Angeles basin," Atmospheric Environment, vol. 29, no. 13, pp. 1499-1518, 1995.

[29] X. Hu, S. Liu, F. Liang et al., "Observational study of wind fields, temperature fields over Beijing area in summer and winter," 
Acta Scientiarum Naturalium University Pekinensis, vol. 41, no. 3, pp. 399-407, 2005.

[30] J.-J. Baik, S.-B. Park, and J.-J. Kim, "Urban flow and dispersion simulation using a CFD model coupled to a mesoscale model," Journal of Applied Meteorology and Climatology, vol. 48, no. 8, pp. 1667-1681, 2009.

[31] Y. Miao, S. Liu, B. Chen et al., "Simulating urban flow and dispersion in Beijing by coupling a CFD model with the WRF model," Advances in Atmospheric Sciences, vol. 30, no. 6, pp. 1663-1678, 2013. 

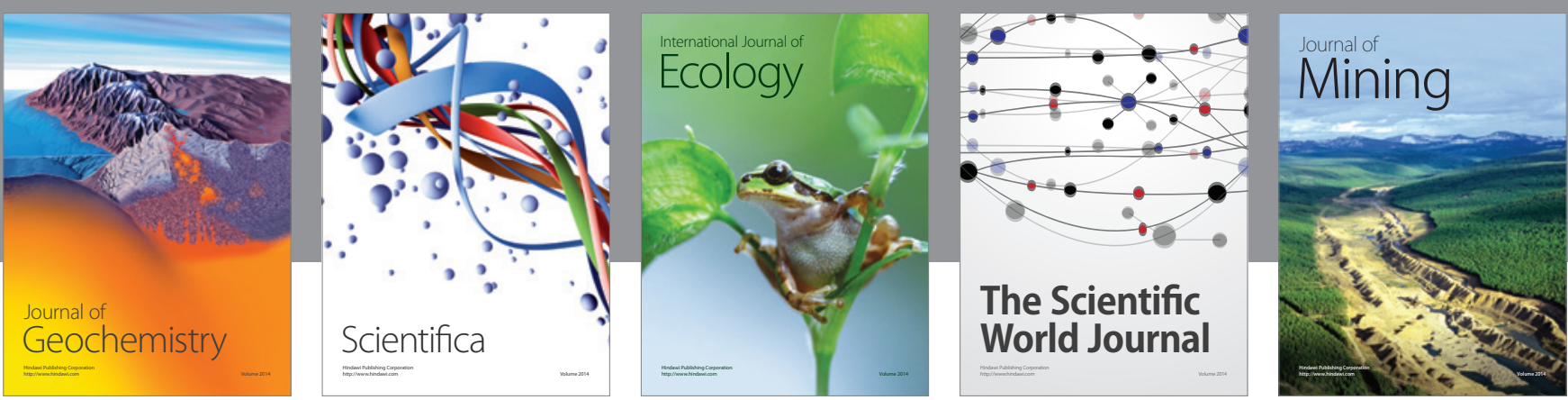

The Scientific World Journal
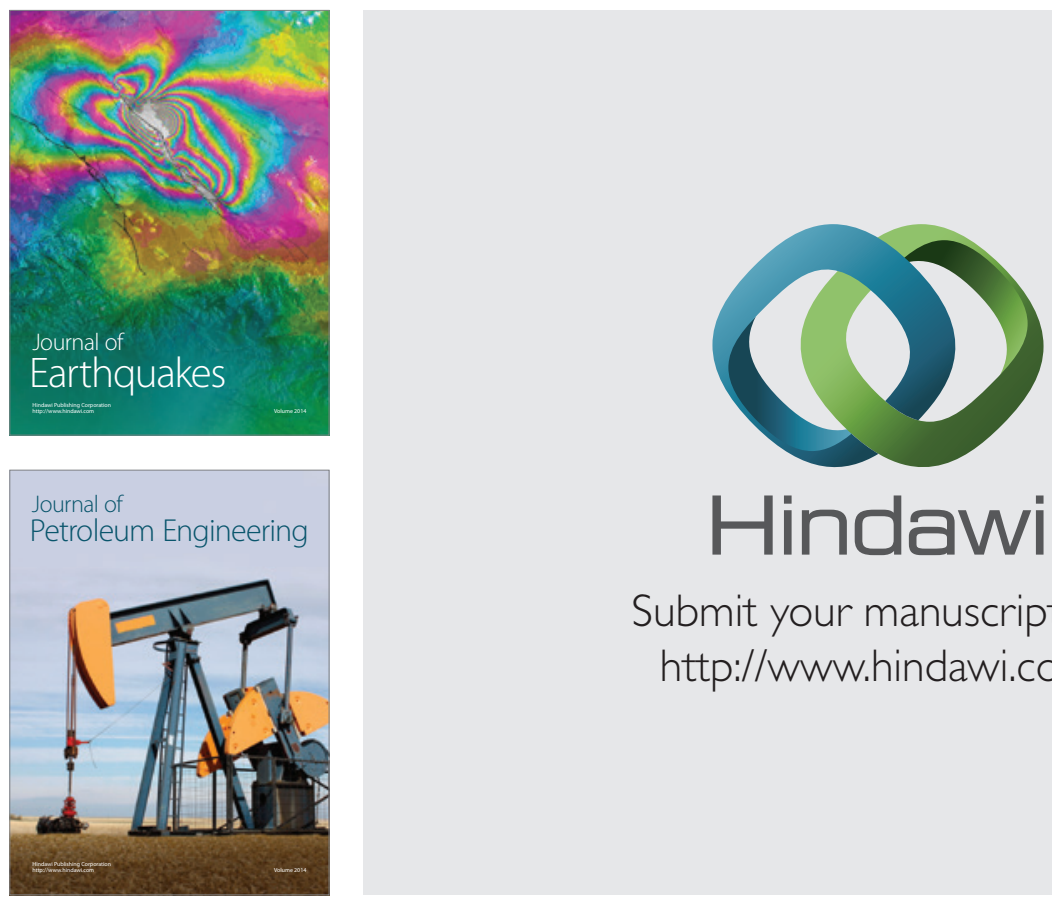

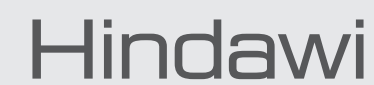

Submit your manuscripts at

http://www.hindawi.com
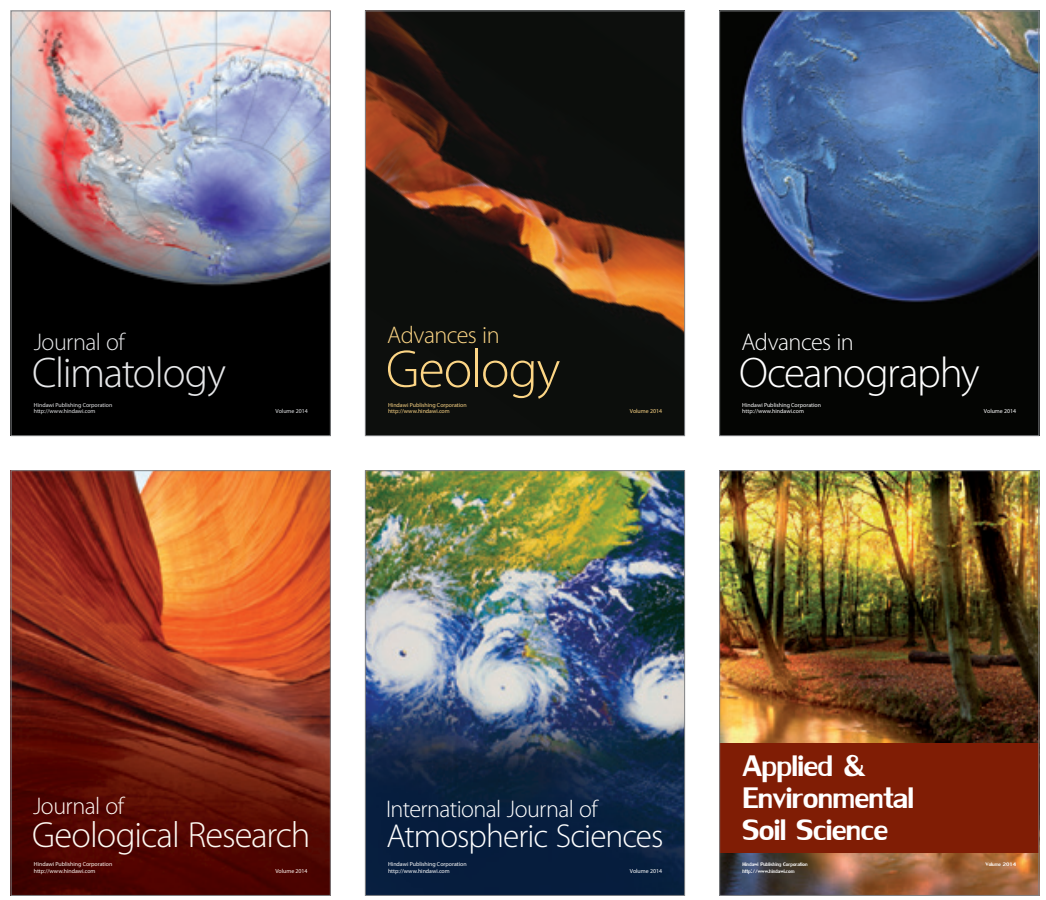
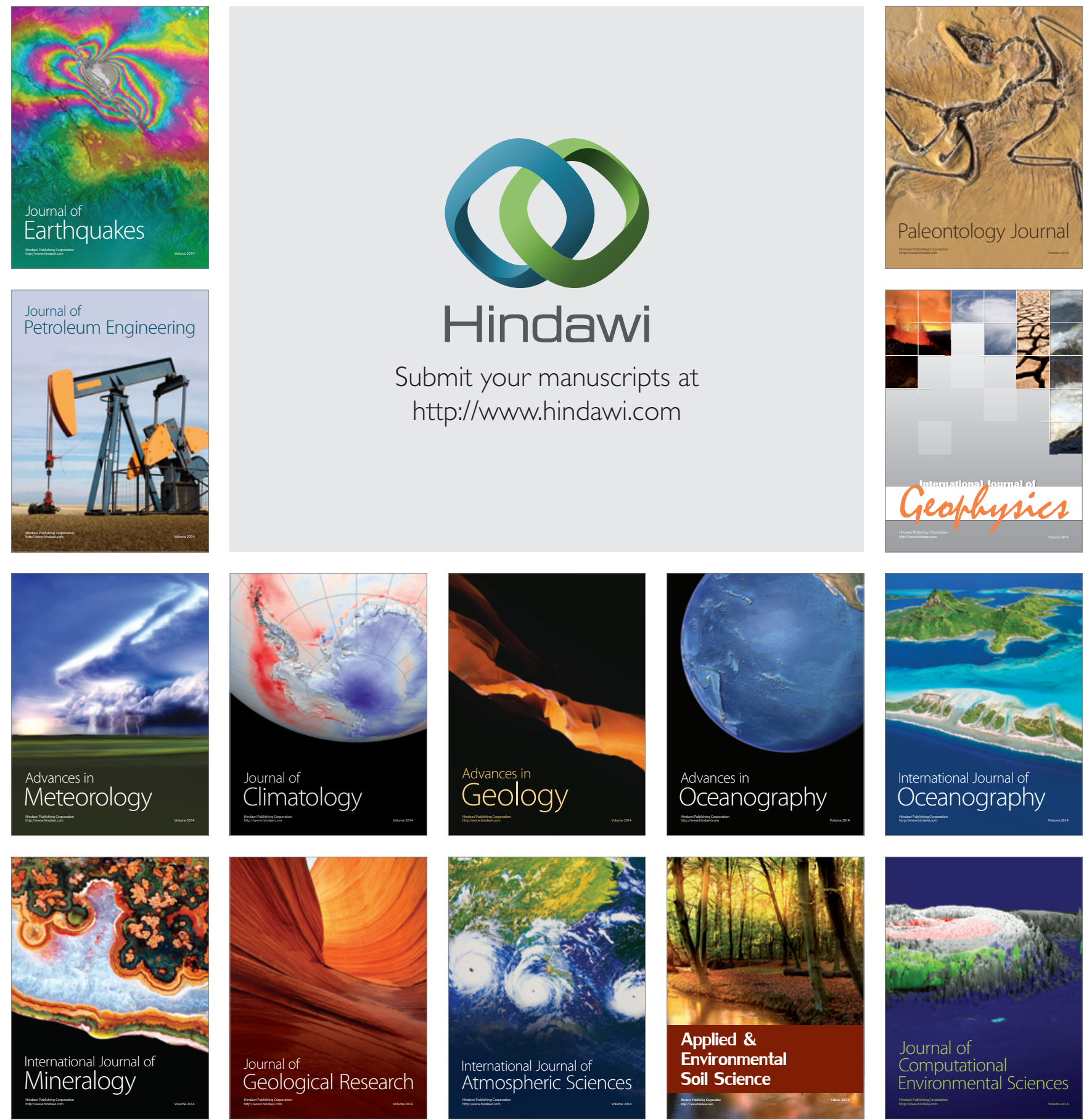